\title{
Muscarinic Acetylcholine Receptors and M-Currents Underlie Efferent-Mediated Slow Excitation in Calyx-Bearing Vestibular Afferents
}

\author{
이. Chris Holt, ${ }^{1,2,3}$ Paivi M. Jordan, ${ }^{1}{ }^{\circledR}$ Anna Lysakowski, ${ }^{4,5}$ Amit Shah, ${ }^{1}$ - Kathy Barsz, ${ }^{1}$ and Donatella Contini ${ }^{1,4}$ \\ Departments of ${ }^{1}$ Otolaryngology, ${ }^{2}$ Neuroscience, and ${ }^{3}$ Pharmacology and Physiology, University of Rochester, Rochester, New York 14642 , and \\ Departments of ${ }^{4}$ Anatomy and Cell Biology and ${ }^{5}$ Otolaryngology, University of Illinois at Chicago, Chicago, Illinois 60612
}

\begin{abstract}
Stimulation of vestibular efferent neurons excites calyx and dimorphic (CD) afferents. This excitation consists of fast and slow components that differ $>100$-fold in activation kinetics and response duration. In the turtle, efferent-mediated fast excitation arises in CD afferents when the predominant efferent neurotransmitter acetylcholine ( $\mathrm{ACh}$ ) activates calyceal nicotinic ACh receptors (nAChRs); however, it is unclear whether the accompanying efferent-mediated slow excitation is also attributed to cholinergic mechanisms. To identify synaptic processes underlying efferent-mediated slow excitation, we recorded from $\mathrm{CD}$ afferents innervating the turtle posterior crista during electrical stimulation of efferent neurons, in combination with pharmacological probes and mechanical stimulation. Efferent-mediated slow excitation was unaffected by $n A C h R$ compounds that block efferent-mediated fast excitation, but were mimicked by muscarine and antagonized by atropine, indicating that it requires $\mathrm{ACh}$ and muscarinic $\mathrm{ACh}$ receptor $(\mathrm{mAChR})$ activation. Efferent-mediated slow excitation or muscarine application enhanced the sensitivity of $\mathrm{CD}$ afferents to mechanical stimulation, suggesting that $\mathrm{mAChR}$ activation increases afferent input impedance by closing calyceal potassium channels. These observations were consistent with suppression of a muscarinic-sensitive $\mathrm{K}^{+}$-current, or $\mathrm{M}$-current. Immunohistochemistry for putative M-current candidates suggested that turtle CD afferents express KCNQ3, KCNQ4, and ERG1-3 potassium channel subunits. KCNQ channels were favored as application of the selective antagonist XE991 mimicked and occluded efferent-mediated slow excitation in $\mathrm{CD}$ afferents. These data highlight an efferent-mediated mechanism for enhancing afferent sensitivity. They further suggest that the clinical effectiveness of $\mathrm{mAChR}$ antagonists in treating balance disorders may also target synaptic mechanisms in the vestibular periphery, and that $\mathrm{KCNQ}$ channel modulators might offer similar therapeutic value.
\end{abstract}

Key words: acetylcholine; calyx; M-current; muscarinic; vestibular afferent; vestibular efferent

Significance Statement

Targeting the efferent vestibular system (EVS) pharmacologically might prove useful in ameliorating some forms of vestibular dysfunction by modifying ongoing primary vestibular input. EVS activation engages several kinetically distinct synaptic processes that profoundly alter the discharge rate and sensitivity of first-order vestibular neurons. Efferent-mediated slow excitation of vestibular afferents is of considerable interest given its ability to elevate afferent activity over an extended time course. We demonstrate for the first time that efferent-mediated slow excitation of vestibular afferents is mediated by muscarinic acetylcholine receptor $(\mathrm{mAChR})$ activation and the subsequent closure of KCNQ potassium channels. The clinical effectiveness of some anti-mAChR drugs in treating motion sickness suggest that we may, in fact, already be targeting the peripheral EVS.

\section{Introduction}

The efferent vestibular system (EVS) originates as a small neuronal cluster within the dorsal brainstem, located bilaterally in close

Received July 21, 2016; revised Jan. 9, 2017; accepted Jan. 10, 2017.

Author contributions: J.C.H. and P.M.J. designed research; J.C.H., P.M.J., A.L., A.S., K.B., and D.C. performed research; J.C.H., A.L., A.S., K.B., and D.C. analyzed data; J.C.H., P.M.J., and A.L. wrote the paper.

This work was supported by National Institutes of Health/National Institute on Deafness and Other Communication Disorders Grants R01-DC-008981 (J.C.H.); R01-DC-02521 and DC-02058 (to A.L.); and P30-DC-005409 (to Center for Communicative and Navigational Sciences, University of Rochester). We thank the University of Rochester Medical Center Confocal and Conventional Microscopy Core for their help in acquiring immunohistochemical images, Dr. proximity to the abducens nucleus and genu of the facial nerve. EVS neurons project to the ipsilateral and/or contralateral ear via cranial nerve VIII to provide a dense centrifugal innervation

\footnotetext{
Paul Allen for advice on statistical analyses, Steven D. Price for immunohistochemistry expertise, and Marcin Klapczynski for performing Western blots to confirm antibody specificity.

The authors declare no competing financial interests.

Correspondence should be addressed to J. Chris Holt, Department of Otolaryngology, University of Rochester, 601 Elmwood Avenue, Box 603, Rochester, NY 14642. E-mail: joseph_holt@urmc.rochester.edu.

DOI:10.1523/JNEUROSCI.2322-16.2017

Copyright $\odot 2017$ the authors $\quad 0270-6474 / 17 / 371873-15 \$ 15.00 / 0$
} 
to every vestibular end organ (Meredith, 1988; Lysakowski and Goldberg, 2004). Within neuroepithelia, EVS neurons undergo extensive branching to produce numerous presynaptic varicosities on hair cells and afferent processes (Smith and Rasmussen, 1968; Sans and Highstein, 1984; Lysakowski and Goldberg, 1997; Purcell and Perachio, 1997; Jordan et al., 2015). Using these synaptic connections, EVS activation profoundly modulates the firing rates and sensitivity of primary vestibular afferents (Goldberg and Fernández, 1980; Rossi et al., 1980; Boyle and Highstein, 1990).

Vestibular afferent responses to EVS stimulation are diverse and are routinely classified according to the rate and direction of changes in the afferent's resting discharge (Goldberg and Fernández, 1980; Rossi et al., 1980; Highstein and Baker, 1985; Brichta and Goldberg, 2000b; Chagnaud et al., 2015). Efferent-mediated changes in afferent activity include fast inhibition, fast excitation, and slow excitation. Efferent-mediated fast inhibition and excitation have latencies of several milliseconds and typically peak and decay within 100-300 ms of stimulus presentation (Goldberg and Fernández, 1980; Highstein and Baker, 1985; Holt et al., 2006a; Boyle et al., 2009). Efferent-mediated slow excitation, however, exhibits longer latencies, requires tens of seconds to peak, and can persist for minutes after stimulus termination. That each component can be differentially activated or appear in combination, under varying efferent stimuli and/or in different afferent classes, suggests that they may use different EVS synaptic processes (Goldberg and Fernández, 1980; Boyle and Highstein, 1990; Brichta and Goldberg, 2000b; Marlinski et al., 2004; Holt et al., 2015a,b).

EVS neurons are predominantly cholinergic (Kong et al., 1994; Bridgeman et al., 1996; Popper et al., 2002; Pujol et al., 2014; Jordan et al., 2015), but they also express calcitonin generelated peptide (CGRP), ATP, and opioid peptides (Perachio and Kevetter, 1989; Ryan et al., 1991; Aubert et al., 1994; Marco et al., 1996; Popper et al., 2004; Luebke et al., 2014). Timing differences among fast and slow excitation suggest differential recruitment of ionotropic and metabotropic neurotransmitter receptors, respectively. This suggestion has held true for efferent-mediated fast inhibition and excitation. Efferent-mediated afferent inhibition is attributed to sequential activation of calcium-permeable, $\alpha 9$-containing nicotinic acetylcholine (ACh) receptors $\left(\alpha 9^{\star} \mathrm{nAChRs}\right)$ and small-conductance, calcium-dependent potassium channels (SK) on type II hair cells. SK activation hyperpolarizes hair cells to reduce transmitter release and disfacilitate afferent firing (Holt et al., 2001, 2006a, 2015b). In contrast, efferent-mediated fast excitation of vestibular afferents is attributed to nAChRs whose activation enhances transmitter release from type II hair cells and/or directly depolarizes the afferent (Rossi et al., 1980; Bernard et al., 1985; Highstein and Baker, 1985; Sugai et al., 1991; Holt et al., 2006a, 2015b). Extensive pharmacological and molecular biological data indicate that these excitatory nAChRs contain $\alpha 4, \alpha 6$, and $\beta 2 \mathrm{nAChR}$ subunits (Guth et al., 2002; Holt et al., 2003, 2006a, 2015b).

Unlike efferent-mediated fast inhibition and excitation, the EVS neurotransmitter and receptor mechanisms driving efferentmediated slow excitation remain unidentified. Cholinergic or opioid agonists, CGRP, or ATP can generate slow afferent excitation in hair cell preparations (Sewell and Starr, 1991; Aubert et al., 1994; Bailey and Sewell, 2000; Vega and Soto, 2003; Pérez et al., 2009). Activation of $\alpha 9^{\star}$ nAChRs also generates slow responses in the cochlea (Sridhar et al., 1997). However, efferent-mediated slow excitation has not been directly chal- lenged pharmacologically to identify whether ACh or some other EVS neurotransmitter is responsible.

In this article, a combination of electrophysiological, selective pharmacological, and immunohistochemical (IHC) approaches was used to further characterize efferent-mediated responses of calyx and dimorphic (CD) afferents innervating the turtle posterior crista. The goals were as follows: (1) to resolve whether the release of ACh is involved in efferent-mediated slow excitation of CD afferents; (2) to identify what receptor mechanisms are used; and (3) to specify what downstream signaling components are required.

\section{Materials and Methods}

Tissue preparation. A total of 47 red-eared slider turtles (Trachemys scripta elegans, $100-600 \mathrm{~g}, \sim 7-20 \mathrm{~cm}$ carapace length) of either sex (25 males, 22 females) were deeply anesthetized with sodium pentobarbital. Upon loss of reflexes, turtles were decapitated and the head was split along the sagittal plane. The two halves were immediately placed in an oxygenated control solution as follows (in $\mathrm{mm}$ ): $105 \mathrm{NaCl}, 4 \mathrm{KCl}, 0.8$ $\mathrm{MgCl}_{2}, 2 \mathrm{CaCl}_{2}, 25 \mathrm{NaHCO}_{3}, 2 \mathrm{Na}$-pyruvate, 0.5 glutamine, and 10 glucose, $\mathrm{pH} 7.2-7.3$ during continuous bubbling with $95 \% \mathrm{O}_{2} / 5 \% \mathrm{CO}_{2}$. Typically, the left half was used for nerve recordings (Holt et al., 2006a,b), while the right side was used for IHC procedures. In some instances, both halves were used for IHC procedures. For IHC, vestibular tissue was prepared by either extracting whole labyrinths from the inner ear and drop fixing in $4 \%$ paraformaldehyde (PFA), or perfusing the labyrinth with $4 \%$ PFA, $1 \%$ acrolein, $1 \%$ picric acid, and $5 \%$ sucrose in control solution before extraction. All procedures involving animals were performed in accordance with recommendations made by the National Institutes of Health (NIH) Guide for the Care and Use of Laboratory Animals and were approved by the University Committee for Animal Resources at the University of Rochester, and the Institutional Animal Care and Use Committee at the University of Illinois at Chicago (UIC).

Nerve recording setup. All neurophysiological procedures were conducted at room temperature (i.e., $21-23^{\circ} \mathrm{C}$ ). The methods used here are similar to previous descriptions (Holt et al., 2006a,b, 2007, 2015b). Remaining brain in the left half-head was blocked transversely between the levels of the trigeminal and glossopharyngeal nerves. These nerves as well as the vagus were extracted, and the surrounding bone was then removed to provide direct access to the bony plate encapsulating the posterior ampulla. Here, a metal pick was used to create a small fenestra to expose the posterior ampullary nerve and its branches to each of the two ends of the crista epithelium (i.e., to each hemicrista). Connective tissues covering the nerve were subsequently removed with a fine tungsten hook. The half-head preparation was immobilized in a recording chamber using cyanoacrylate, and the exposed posterior ampullary nerve was continuously superfused with oxygenated control solution from a gravity-fed pipette capable of delivering solutions at 3-4 $\mu \mathrm{l} / \mathrm{s}$ from any one of six $10 \mathrm{ml}$ reservoirs.

Borosilicate sharp microelectrodes (Sutter Instruments), 40-120 M $\Omega$, containing $3 \mathrm{M} \mathrm{KCl}$, were connected to the headstage of a preamplifier (Biomedical Engineering), and microelectrode capacitance was neutralized by driving the shield of the input cable. These electrodes have been successfully used to acquire extracellular and/or intracellular recordings from turtle vestibular afferents (Brichta and Goldberg, 2000a,b; Holt et al., 2006a,b, 2015b). Microelectrodes were advanced in $5 \mu \mathrm{m}$ steps with an Inchworm drive mounted on a three-axis micromanipulator (EXFO Burleigh Products Group). Recordings were made from the posterior ampullary nerve just as it bifurcates to innervate the two hemicristae (Holt et al., 2006a,b).

Efferent stimulation. Electrical stimulation of efferent fibers was used to classify afferents (Brichta and Goldberg, 2000b; Holt et al., 2006a, 2015b). Efferent fibers innervating the posterior crista travel in a small nerve bundle called the cross-bridge that extends from the anterior to the posterior divisions of the eighth nerve. During the dissection process, bundle access was facilitated by removing an adjacent bony ridge just rostral to the lagena. The potential for muscle contractions during stimulation was avoided by removing jaw muscles and severing the facial 
nerve at its entrance into the facial canal (Terry, 1920). Electrodes used for efferent stimulation were constructed from Teflon-coated silver wires (AG10T, MedWire), whose tips were stripped of insulation and chlorided. The cathode was positioned on the cross-bridge, and the reference electrode was placed on adjacent bone. Electrical stimuli consisted of trains of $100 \mu$ s constant-current shocks delivered from a stimulus isolator (model A360. World Precision Instruments) to the two electrodes. Efferent shock artifacts in raw records were canceled off-line by subtracting a computed artifact average waveform at known shock times.

Indentation of the posterior canal. We used an indenter to deliver mechanical stimuli to the posterior canal. The indenter was constructed from tapered borosilicate glass tubing where one end was fire polished and flattened to create a contact area of $0.1-0.2 \mathrm{~mm}^{2}$. This glass tube was attached to a closed-loop, preloaded piezo actuator (P-841.60, Physik Instrumente), whose movements were directed and monitored using a piezo servo-controller (E625.SR, Physik Instrumente). The piezo actuator is equipped with an inline position sensor whose output was used to track the displacement of the indenter. Maximum displacement was $\pm 45 \mu \mathrm{m}$. During the initial dissection, an aperture was made in the temporal bone to expose a segment of the membranous posterior canal duct near the common crus. The indenter assembly was positioned using a three-axis micromanipulator until the flattened glass tip made direct contact with the exposed posterior canal duct. The indenter tip was then slowly advanced 50-100 $\mu \mathrm{m}$ to ensure continuous mechanical coupling with the duct during stimulation.

Physiological testing and afferent response analysis. In this study, extracellular spike activity was obtained exclusively from posterior canal afferents under various experimental and pharmacological treatments (see Pharmacological solutions). The resulting records were high-pass digitally filtered ( $159 \mathrm{~Hz}$ corner frequency), after which an appropriate spike detection threshold was set to specify corresponding spike times. Spike times were then binned and averaged to construct afferent response histograms during efferent stimulation, indentation, or both. Bin sizes for each condition are provided in subsequent paragraphs.

In all afferent recordings, $\geq 3 \mathrm{~s}$ of background activity were recorded before one of two different stimulus protocols was delivered to efferent nerve fibers in the cross-bridge. The efferent stimulus either involved the administration of repeated, short shock trains (i.e., $100 \mathrm{~ms}$ ) consisting of 20 shocks at $200 \mathrm{~Hz}$, or a longer $10 \mathrm{~s}$ shock train consisting of 1000 shocks at $100 \mathrm{~Hz}$. For each new afferent recording, the short shock train protocol was always used first. Here, several trains were presented and shock amplitude was adjusted to determine the threshold as well as the maximal stimulus amplitude that avoided antidromic activation of afferents. Because of the relative proximity of the cross-bridge to the posterior branch of the eighth cranial nerve, antidromic activation of posterior crista afferents was occasionally observed during larger-amplitude efferent stimuli and/or pooling of control solution around the cross-bridge. In these few experiments, current spread from the efferent electrode was minimized by reducing stimulus amplitudes and/or wicking/redirecting the excess fluid. For short shock trains, intertrial intervals were set at 3-5 s to allow fast efferent-mediated changes in afferent discharge to return to prestimulus values before delivery of the next efferent shock train. Stimulus thresholds ranged from 15 to $100 \mu \mathrm{A}$, and maximal current amplitudes ranged from 50 to $400 \mu \mathrm{A}$ (i.e., three to four times threshold).

Afferent responses to short efferent shock trains were calculated by specifying spike times from $500 \mathrm{~ms}$ before each train to a minimum of $2.5 \mathrm{~s}$ after each train. We applied this calculation to all stimulation trials ( $n=10-25$ ) within a single run under each condition (e.g., control vs drug) and generated a mean perstimulus response plotted as an average response histogram segmented into $50 \mathrm{~ms}$ bins. Spike times for afferent responses to long efferent shock trains were displayed as continuous rate histograms segmented into $200 \mathrm{~ms}$ bins. In all histograms, the total number of spikes for each bin was converted to the discharge rate after dividing by the corresponding bin width. The mean amplitude of efferent-mediated fast excitation was calculated from the first $100 \mathrm{~ms}$ segment of the average response histogram immediately following short efferent shock trains (Brichta and Goldberg, 2000b; Holt et al., $2015 \mathrm{~b}$ ) and/or the entire $10 \mathrm{~s}$ stimulation period in continuous rate histograms.
The mean peak amplitude of efferent-mediated slow excitation was calculated from continuous rate histograms generated with either short or long efferent shock trains. Average discharge rates were taken from a 5-10 s continuous window centered on the peak of the slow component that was located at a minimum of $2 \mathrm{~s}$ beyond the preceding efferent stimulus to avoid contamination from efferent-mediated fast excitation. During short efferent shock trains, in instances where the peak of efferent-mediated slow excitation overlapped with trials of efferentmediated fast excitation, the window of peak slow excitation was stitched from 5 to 10, 1-s prestimulus segments, again to avoid contamination from fast excitatory transients. In a few examples during indentation, the peak window was calculated after subtracting sinusoidal transients. Start and stop times were determined by identifying the intersection of mean prestimulus discharge rates with linear fits to the buildup or decay of efferent-mediated slow excitation. Measurements of time-to-peak and duration were derived from the peak minus the start time and the stop time minus the start time, respectively. All reported values of peak efferent-mediated fast and slow excitation reflect a subtraction of mean background discharge rates taken from the prestimulus interval of average response histograms or the first $5 \mathrm{~s}$ segment (i.e., $\alpha$ period) of each trial preceding the initial onset of efferent stimulation.

We also investigated the effects of efferent stimulation or pharmacological agents on afferent responses to indentation. Previous studies (Dickman and Correia, 1989; Rabbitt et al., 1995; Holt et al., 2006b) have demonstrated that the dynamics of afferent discharge during indenter displacement correspond to those resulting from angular head velocity. We first collected a $5 \mathrm{~s}$ sample of afferent background activity followed by the response to $12-18$ cycles of a $0.3 \mathrm{~Hz}$ sinusoidal indentation of the canal duct under control conditions. This control response was then compared with the subsequent response of the afferent to a segment of $12-18$ cycles of the same indentation stimulus taken during peak efferent-mediated responses and return to prestimulus values or peak pharmacological effects and washout. The amplitude and phase of the sinusoidal indentation were acquired by fitting a sine wave to the indenter displacement signal. Spike times for the second and subsequent sine-wave cycles were identified and displayed as individual phase histograms ( 40 bins, each $83.3 \mathrm{~ms}$ wide) in sync with the calculated phase of indenter displacement. The total number of spikes for each bin was converted to the discharge rate after dividing by bin width. These individual phase histograms were each fitted with a single-cycle sine wave. Gains for each wave were tabulated as the ratio of the fitted amplitudes of the afferent response (in spikes per second) and associated indenter displacement (in micrometers). Phases were presented as the difference (in degrees) between each wave response and indenter phase where positive phases reflect response phase leads. The mean gain and phase were calculated by averaging individual gains and phases from each unit under each condition. To ensure that the response of each afferent remained linear during indentation, we identified the appropriate indentation amplitude that minimized inhibitory cutoff and/or excitatory skew. In a few examples where there were missing bins during the inhibitory segments, gains and phases were based on fitting sine waves to the excitatory halfcycle only.

Data acquisition and computer processing. Data acquisition, efferent stimuli, and indenter displacement were controlled using a PC with custom-made Spike2 scripts and a micro1401 interface (version 6, Cambridge Electronic Design). Microelectrode signals were low-pass filtered at $1 \mathrm{kHz}$ (four-pole Bessel; model 432, Wavetek) and sampled at $10 \mathrm{kHz}$ by a 12 bit analog-to-digital converter. Delivery of efferent shock trains was controlled from a digital output port. Spike2 data files were first exported as general text files and then processed using custom macros written in IgorPro 6.37 (WaveMetrics).

Pharmacological solutions. The nAChR ligands, cytisine (CYT), 1,1-dimethyl4-piperazinium (DMPP), epibatidine, and 2,2,6,6-tetramethylpiperdin-4-yl heptanoate (TMPH), and the KCNQ antagonist 10,10-bis(4-pyridinylmethyl)$9(10 \mathrm{H})$-anthracenone dihydrochloride (XE991) were obtained from Tocris Bioscience. The muscarinic ACh receptor (mAChR) ligands atropine and muscarine were obtained from Sigma-Aldrich. All drugs were prepared as concentrated stock solutions in ultrafiltered water and frozen. Before each experiment, aliquots were thawed and the appropriate 
volume was added to the control solution to achieve the desired working concentration. Most pharmacological agents usually took $30 \mathrm{~s}$ to $2 \mathrm{~min}$ to begin acting and another $2-5 \mathrm{~min}$ to reach maximal effect. Washout times were variable and could be longer than $10 \mathrm{~min}$. Reversibility for most compounds was demonstrated within a single afferent recording session or from subsequent recordings in a single preparation.

Statistical procedures. All statistical analyses were performed in GraphPad Prism (version 6.0 h; GraphPad Software). Unless otherwise stated, values are expressed as the mean \pm SEM. One-sample $t$ tests were used to evaluate whether means differed from zero. Differences in afferent response properties (e.g., amplitude, time-to-peak, excitatory slopes, and duration) to stimulation protocols or drug effects were evaluated with paired $t$ tests. Correlations between response amplitude and duration during two efferent stimulation protocols were also performed. During indentation experiments, single-cycle gains and phases were each subjected to repeated measures two-way ANOVAs with the factors "cycle number" and the presence/absence of efferent-mediated slow excitation, muscarine-mediated excitation, or XE991-mediated excitation. Since the main effect of cycle number was not significant for either gain or phase, these are collapsed across cycle number, and marginal means for gain and phase are presented in the Results.

IHC studies. Freshly fixed semicircular canal cristae were placed in $30 \%$ sucrose for at least $1 \mathrm{~h}$ at $4^{\circ} \mathrm{C}$ and then embedded in a gelatin mold ( $12 \%$ gelatin prepared in $30 \%$ sucrose) and chilled at $4^{\circ} \mathrm{C}$. Upon solidification, the gelatin block was mounted on the stage of a freezing sliding microtome, and 35-40 $\mu \mathrm{m}$ frozen sections were subsequently cut and transferred to a collection vial. The collection vial was warmed to dissolve the gelatin, and remaining tissue sections were rinsed with $0.1 \mathrm{M} \mathrm{PB}$. In some experiments, preliminary treatments included a $10 \mathrm{~min}$ incubation in an aqueous $1 \% \mathrm{Na}$ borohydride solution and $1 \mathrm{~h}$ in a blocking solution ( $1 \%$ teleost fish gelatin, $1 \%$ bovine serum albumin, and $0.5 \%$ Triton X-100 in PBS). For the remaining IHC experiments, tissue was blocked in 5\% normal donkey serum (Jackson ImmunoResearch) prepared in $0.5 \%$ Triton X-100 and $0.1 \mathrm{M} \mathrm{PB}$. After block, the tissue sections were then incubated $16-48 \mathrm{~h}$ with primary antibodies (see Antibodies below). Following several rounds of $0.1 \mathrm{M}$ PB washes, sections were incubated with Alexa Fluor-conjugated secondary antibodies (Invitrogen) at 1:200 to 1:500 dilutions in $0.1 \mathrm{M} \mathrm{PB}$ for $2-3 \mathrm{~h}$ in the dark at room temperature. Sections were again washed several times with $0.1 \mathrm{M}$ $\mathrm{PB}$ and reacted with DAPI (1:1000 of a $1 \mathrm{mg} / \mathrm{ml}$ solution; Sigma-Aldrich) for $5 \mathrm{~min}$ followed by a brief wash in distilled $\mathrm{H}_{2} \mathrm{O}$. Using an eyelash probe, final tissue sections were transferred to Plus Slides (Fisher Scientific) and coverslipped with SlowFade Gold (Invitrogen), Mowiol (Calbiochem), or Vectashield (Vector Laboratories). Stained cristae were visualized on an FV1000 microscope (Olympus America) in the University of Rochester Medical Center Confocal and Conventional Microscopy Core or on a Zeiss LSM 510 META laser-scanning confocal microscope (Carl Zeiss) at UIC. Confocal images were captured with Olympus Fluoview or Zeiss LSM 5 Image Browser proprietary software and exported as TIFF files. Sizing and labeling of digital TIFF images were done with Photoshop and Illustrator (Adobe).

Antibodies. The anti-synapsin antibody used in this study [polyclonal (rabbit); AB1543, Millipore; RRID: AB_2200400] was derived from synapsin I extracts purified from bovine brain. Synapsin antibodies have been used to demarcate efferent varicosities in rat, mouse, and guinea pig cochlea (Bergeron et al., 2005; Layton et al., 2005; Lopez et al., 2008) as well as the vestibular endorgans of toadfish, frog, and turtle (Holstein et al., 2005; Castellano-Muñoz et al., 2010; Jordan et al., 2015). Calretinin [CR; polyclonal (goat); AB1550, Millipore; RRID: AB_90764, 1:1000 dilution] was used to label type II hair cells near the planum, calyx and dimorphic afferents in the central zone (CZ), and bouton afferents near the torus region (Monk and Peterson, 1995; Huwe et al., 2011; Jordan et al., 2015).

For KCNQ4, we used antiserum generated with the peptide sequence CSISRSVSTNMD-COOH from its C terminus (a gift from B. Kachar, $\mathrm{NIH}$, Bethesda, MD). For KCNQ3, we used antiserum generated with a peptide corresponding to residues 668-686 of rat KCNQ3 [polyclonal (rabbit); AB5483, Millipore Bioscience Research Reagents; RRID: AB_177492]. Anti-erg1 [polyclonal (rabbit); AB5222, Millipore Bioscience Research Reagents; RRID: AB_2132144] made against a purified peptide consisting of amino acid residues 1121-1137 from rat Erg1. Erg2 antiserum [polyclonal (rabbit); APC-114, Alomone Labs; RRID: AB_2039842] were generated against the amino acid residues 185-198 (TLNFVEFNLEKHRSC) of human Erg2, whereas antibodies to Erg3 [polyclonal (rabbit); APC-112, Alomone Labs; RRID: AB_2039937] were generated against amino acid residues 1108-1123 (CPEFLDLEKSKLK SKE) of rat Erg3. The above KCNQ and ERG antibodies have been used successfully to label calyceal afferents and hair cells in the mammalian vestibular periphery (Hurley et al., 2006; Sousa et al., 2009; Lysakowski et al., 2011). Specificity for antibodies against ERG2, ERG3, and KCNQ4 were confirmed by Western blot in turtle whole brain and vestibular organs, and compared with parallel Western blots in rat tissues (data not shown). Negative controls included the deletion of primary antibodies.

\section{Results}

In the turtle posterior crista, both hair cell and afferent morphology have been used to partition the neuroepithelium into a central zone and a peripheral zone (Brichta and Peterson, 1994; Brichta and Goldberg, 2000a). Type II hair cells and associated bouton afferents are dispersed throughout the crista whereas type I hair cells, innervated by CD afferents, are confined to the central zone. Bouton afferents (B) are further delineated as BT, BM, or $\mathrm{BP}$ afferents depending on whether their terminal fields primarily localize near the torus $(\mathrm{T})$, middle $(\mathrm{M})$, or planum $(\mathrm{P})$ regions of the crista, respectively. Here, as in previous studies, afferents were classified (i.e., BT, BM, BP, and CD) according to their characteristic response to efferent stimulation (Brichta and Goldberg, 2000b; Holt et al., 2006a, 2015b). CD afferents are excited while BT/BM afferents are inhibited. BP afferents are weakly excited but were not included in this study. In 47 preparations, extracellular sharp electrode recordings were obtained from a total of 209 posterior crista afferents (127 CD, $82 \mathrm{BT} / \mathrm{BM})$ under various combinations of electrical stimulation of vestibular efferents, vestibular stimulation, and pharmacological interrogation.

\section{Efferent stimulation generates two distinct forms of excitation in CD afferents}

Repeated delivery of short efferent shock trains (20 shocks at 200/s every 3-5 s) excited CD afferents along two time scales. The first excitation, characterized as fast, was demarcated by a burst of action potentials at the onset of each efferent stimulus (Fig. $1 A, B)$. In the example shown, the resting discharge during efferent-mediated fast excitation was elevated by $>60$ spikes/s within the first $100 \mathrm{~ms}$ and remained above prestimulus discharge rates for nearly a second (Fig. $1 B$, inset). During the same stimulus sequence, a second slower excitation was also observed. This efferent-mediated slow excitation required tens of seconds to develop and was best visualized as a gradual increase in the discharge rate of the afferent within the interstimulus interval (Fig. 1A,B). Efferent-mediated slow excitation in this particular unit increased the resting discharge rate by $\sim 25$ spikes/s and persisted for $>100 \mathrm{~s}$ beyond the last efferent shock train (Fig. $1 B$ ). When using short efferent shock trains, the mean peak amplitude and duration of efferent-mediated fast excitation in 57 CD units was $37.4 \pm 3.0 \mathrm{spikes} / \mathrm{s}$ and $1.25 \pm 0.12 \mathrm{~s}$, respectively, while the mean peak amplitude for efferent-mediated slow excitation was $17.6 \pm 0.9$ spikes/s. In 35 of 57 CD units where the entire efferentmediated slow response was captured, the time-to-peak was $55.0 \pm 3.2 \mathrm{~s}$, and the mean duration was $147.4 \pm 7.4 \mathrm{~s}$. The mean discharge slope, taken from a linear fit of the rising face of the slow excitation in 45 units was $0.385 \pm 0.029$ spikes $/ \mathrm{s}^{2}$ or an average increase of $\sim 4$ spikes/s every $10 \mathrm{~s}$.

It has been shown previously that efferent-mediated fast and slow excitation can also be elicited using longer shock trains 
A
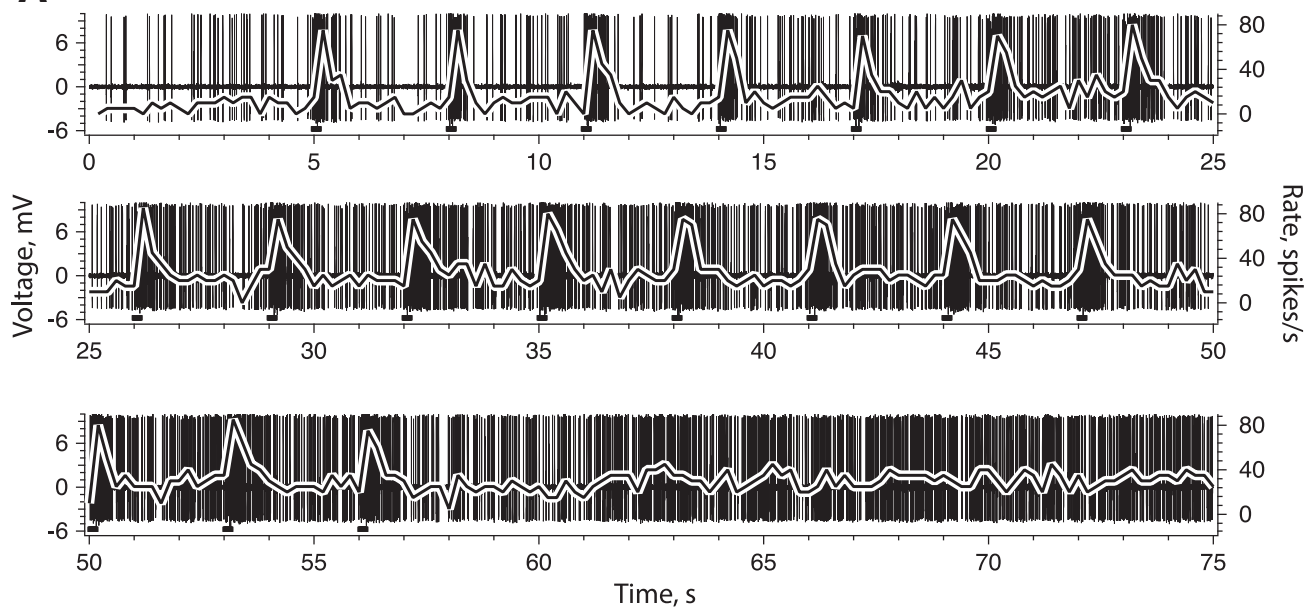

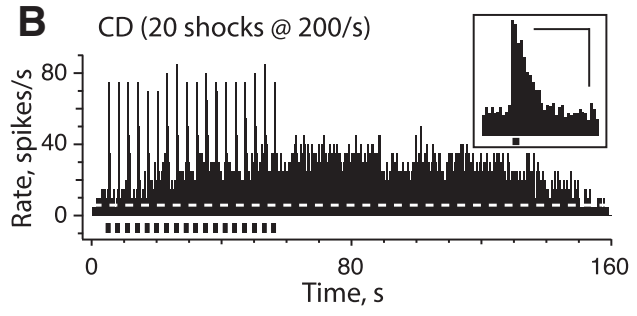

D

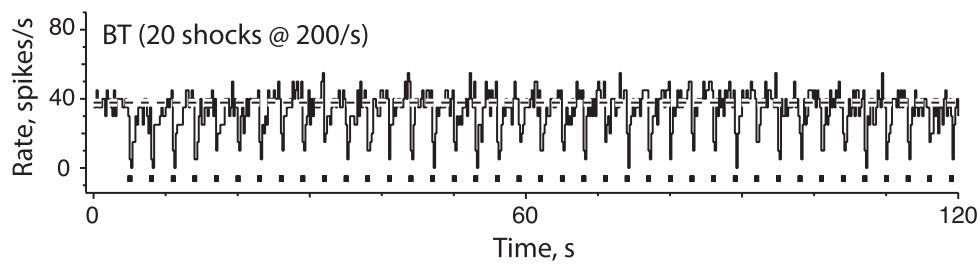

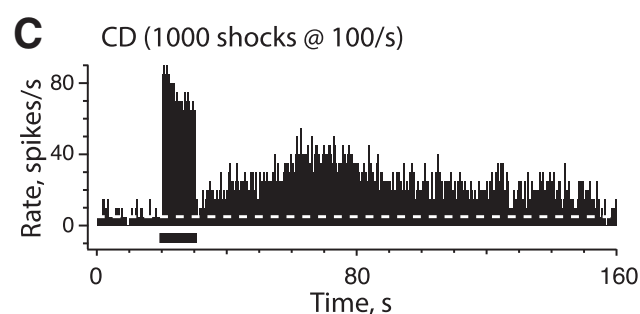

E

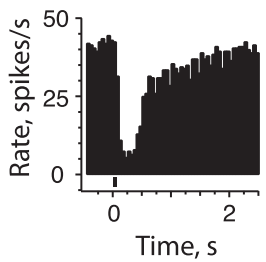

Figure 1. Efferent-mediated excitation of $C D$ afferents develops along two distinct time scales. $A$, High-pass filtered, extracellular spike recording $(t=0$ to 75 s) from $C D$ afferent, during repeated delivery of short efferent shock trains (20 shocks at 200/s, black bars along $x$-axis), is shown. Shock trains were started at $t=5 \mathrm{~s}$, repeated at 3 sintervals, and terminated after 18 trials. Superimposed black line is corresponding continuous rate histogram (in spikes per second; $200 \mathrm{~ms}$ bins, right $y$-axis). $\boldsymbol{B}$, Full-length, continuous rate histogram from $A$ illustrates the time course and overlap of two efferent-mediated excitatory components. Inset, Average response histogram shows the mean efferent-mediated fast excitation in this unit (scale: $x=1 \mathrm{~s}, y=40$ spikes/s). $\boldsymbol{C}$, Continuous rate histogram of same $(D$ afferent to long efferent shock train (1000 shocks at 100/s; black bar). $D$, Full-length, continuous rate histogram taken from a BT afferent during short efferent shock train protocol (black bars). $\boldsymbol{E}$, Average response histogram from the same BT afferent shows the mean perstimulus efferent-mediated inhibition. Dashed horizontal lines in $\boldsymbol{B}-\boldsymbol{D}$ indicate prestimulus discharge rate.

(Brichta and Goldberg, 2000b). In our study, we also used long efferent shock trains and compared these results to those generated with short efferent shock trains. In a subsequent trial from the same CD unit shown in Figure $1, A$ and $B$, the delivery of a single 10 s efferent shock train (1000 shocks at 100/s) also generated fast excitation, which, as with the short protocol, decayed back to prestimulus discharge rates within seconds of stimulus termination (Fig. 1C). With the long shock train, efferentmediated slow excitation was seen as a second distinct increase in discharge rate that developed in earnest after the efferent stimulus. This slow excitation took $50 \mathrm{~s}$ to peak and remained above prestimulus discharge rates for $\sim 130 \mathrm{~s}$. With the long efferent shock train, the mean peak amplitude of efferent-mediated fast excitation in $42 \mathrm{CD}$ units was $35.3 \pm 3.2$ spikes/s, while the mean peak amplitude for efferent-mediated slow excitation was $15.6 \pm$ 1.0 spikes/s. In 41 of $42 \mathrm{CD}$ units, where the entire efferentmediated slow response was captured, the time-to-peak was $43.9 \pm 1.9 \mathrm{~s}$ and the mean duration was $145.4 \pm 7.6 \mathrm{~s}$. The mean discharge slope during long efferent shock trains was $0.389 \pm$ 0.037 spikes $/ \mathrm{s}^{2}$.
We then compared afferent recordings where both efferentmediated fast and slow excitation to the two efferent stimulation protocols (i.e., short vs long) were available for the same unit. The peak amplitudes of fast excitation acquired during the short protocol were positively correlated with the peak amplitudes of fast excitation seen with the long protocol. The Pearson's correlation coefficient $(r)$ for this comparison was $0.626(p=0.0001)$. Across the population, changes in the amplitude of efferent-mediated fast excitation with short shock trains were typically associated with comparable changes in efferent-mediated fast excitation seen with long shock trains. A similar correlation of slow excitatory amplitudes from the two stimulation protocols was also observed $(r=0.648, p<0.0001)$. However, between the two protocols, there were no significant differences in the mean amplitude of fast excitation $(35.3 \pm 3.9$ vs $31.7 \pm 2.7$ spikes $/ \mathrm{s} ; p=$ $0.22, n=36)$ or in the mean amplitude $(17.7 \pm 1.1$ vs $16.4 \pm 1.1$ spikes; $p=0.19, n=36)$, the mean discharge slope $(0.386 \pm$ 0.038 vs $0.445 \pm 0.048$ spikes $/ \mathrm{s}^{2} ; p=0.22, n=29$ ), or the mean duration of slow excitation (160.8 \pm 1.1 vs $153.2 \pm 9.1$ spikes/s; $p=0.50, n=24)$. The one distinction between the two protocols 
was that the mean time for efferent-mediated slow excitation to peak with short efferent shock trains, was significantly longer than the mean time-to-peak for the long efferent shock protocol $(55.7 \pm 4.2$ vs $40.4 \pm 2.3 \mathrm{~s} ; p=0.001, n=24)$. These data suggested that fast and slow excitatory responses generated with either protocol are comparable and that both protocols are likely examining the same phenomena.

The overlap of efferent-mediated fast and slow excitation during delivery of short efferent shock trains initially suggested that the two forms of excitation might be mechanistically related. However, data with long efferent shock trains were not necessarily consistent with that suggestion in that, now, efferentmediated fast and slow excitation were reasonably well separated in time. This indicated that the underlying cellular mechanisms for the two phenomena might be distinct. Two other observations provided additional support for separate mechanisms. First, in this study, nearly one-third of our CD units (40 of 127 units) exhibited a robust efferent-mediated fast excitation during short and/or long efferent shock trains without any indication of an efferent-mediated slow excitation. Second, there was no significant correlation between the amplitudes of fast and slow efferent-mediated excitation with either the short $(r=-0.189$, $p=0.29)$ or the long efferent shock train $(r=0.241, p=0.17)$. Said another way, regardless of the efferent stimulation protocol, the amplitude of efferent-mediated fast excitation was not necessarily predictive of the amplitude of the accompanying efferentmediated slow excitation. These data collectively strengthened the argument that the synaptic mechanisms driving efferentmediated slow excitation differed from those underlying efferentmediated fast excitation.

Efferent-mediated slow excitation is not mediated by nAChRs We then sought to identify what synaptic processes were responsible for generating efferent-mediated slow excitation. Might it be related to one of two cholinergic mechanisms characterized previously in the turtle posterior crista (Holt et al., 2006a, 2015b)? These earlier pharmacological studies demonstrated that efferentmediated inhibition of BT/BM afferents was mediated by the sequential activation of $\alpha 9^{\star} \mathrm{nAChRs}$ and SK that ultimately hyperpolarize type II hair cells. Meanwhile, efferent-mediated fast excitation was initiated by activating $\alpha 4-, \alpha 6$-, and $\beta 2$-containing nicotinic ACh receptors ( $\alpha 4 \alpha 6 \beta 2^{*}$-nAChRs) that result in a direct depolarization of vestibular afferents, particularly CD units (Holt et al., 2006a, 2015b). Since neuronal nAChRs are well noted for their calcium permeability (Vernino et al., 1992, 1994; Haghighi and Cooper, 1998; Lipovsek et al., 2012), we speculated that calcium influx during efferent-mediated fast inhibitory and/or excitatory afferent responses might also engage downstream mechanisms responsible for efferent-mediated slow excitation.

It became apparent early on that a role for $\alpha 9^{\star} n A C h R s$ was unlikely as there was simply little evidence for an efferentmediated slow excitation in most BT/BM afferents. In the same experimental preparations $(n=47)$ from which fast and slow excitatory responses in $\mathrm{CD}$ afferents were readily identified, efferent-mediated inhibitory responses were also routinely observed in BT/BM afferents under comparable efferent stimulation conditions. In the example shown (Fig. $1 D, E$ ), delivery of short efferent shock trains (i.e., 20 shocks at 200/s) robustly inhibited the resting discharge of a BT afferent. Despite repeated delivery of the short efferent shock train for $120 \mathrm{~s}$, the record was devoid of any obvious slow excitatory shifts (Fig. 1D). Such was the case for 77 of $82 \mathrm{BT} / \mathrm{BM}$ recordings. In $\mathrm{BT} / \mathrm{BM}$ recordings where $>50$ s of spike data during efferent stimulation were available, the mean discharge slope was not significantly different than zero $(-0.0105 \pm 0.009, p=0.25, n=56)$. Although efferentmediated slow shifts identified in the remaining five BT/BM units were qualitatively similar to CD afferents, their scarcity prevented further characterization. Given that $\alpha 9^{\star} \mathrm{nAChR}$ activation was not a prerequisite for efferent-mediated slow excitation, we then inquired whether there was a role for the activation of $\alpha 4 \alpha 6 \beta 2^{\star}$-nAChRs.

We reasoned that if efferent-mediated slow excitation required the activation of $\alpha 4 \alpha 6 \beta 2^{\star}$-nAChRs, then it too should be abrogated by cholinergic compounds known to block efferentmediated fast excitation (Holt et al., 2015b). In the CD afferent shown in Figure 2, efferent-mediated fast and slow excitation were generated using repeated short efferent shock trains (20 shocks at 200/s). Application of the nAChR agonist DMPP blocked efferent-mediated fast excitation (Fig. 2A,B) without significantly altering efferent-mediated slow excitation. Note that the effect of efferent-mediated slow excitation is also reflected in the average response histogram (Fig. $2 B$ ) as an elevation of the prestimulus rate compared with the rate seen in the $\alpha$ period (i.e., $t=0-5 \mathrm{~s}$ ) before the onset of efferent stimulation (Fig. 2A). This experiment was repeated in 10 other CD units from nine preparations using several selective blockers of efferent-mediated fast excitation including DMPP, CYT, epibatidine, and TMPH. Greater than $95 \%$ of mean efferent-mediated fast excitation was blocked ( $43.5 \pm 8.7$ vs $1.3 \pm 1.6$ spikes/s; $n=11$; Fig. $2 C$, left) by these compounds, while the mean peak amplitude of efferentmediated slow excitation was not significantly affected (17.1 \pm 1.8 vs $18.8 \pm 2.0$ spikes/s; $n=11$; Fig. $2 C$, right). Together, these physiological and pharmacological data indicate that efferentmediated slow excitation is not mediated by $\alpha 4 \alpha 6 \beta 2^{\star}$ or $\alpha 9^{\star} \mathrm{nAChRs}$.

Calyx and dimorphic afferents in the turtle can be discriminated on the basis of their responses to efferent stimulation following blockade of $\alpha 4 \alpha 6 \beta 2^{\star}$-nAChRs (Holt et al., 2015b). Blockade of efferent-mediated fast excitation in dimorphic afferents unmasks an efferent-mediated inhibition associated with activation of $\alpha 9^{*} \mathrm{nAChR} / \mathrm{SK}$ in type II hair cells. To further understand whether efferent-mediated slow excitation occurs in calyx, dimorphic, or both afferents, we applied the aforementioned criterion to the 11 units following blockade of efferent-mediated fast excitation. Three were dimorphic while the remaining eight were calyx-only afferents. These data suggested that efferent-mediated slow excitation occurs in both morphological classes.

\section{Efferent-mediated slow excitation in CD afferents is mediated by mAChRs}

As in other vertebrate systems, EVS neurons in turtle are predominantly cholinergic (Meredith, 1988; Lysakowski and Goldberg, 2004; Jordan et al., 2015). Thus, it follows that if ACh is also responsible for the activation of efferent-mediated slow excitation, then it must either be attributed to $\mathrm{mAChRs}$ or some other, as yet undefined, nAChR. Since the kinetics of activation and the protracted time course seen in these experiments were certainly more consistent with a metabotropic process, we decided to investigate the role of $\mathrm{mAChRs}$ in the generation of efferentmediated slow excitation using two pharmacological approaches. First, we explored the sensitivity of $\mathrm{CD}$ afferents to the general $\mathrm{mAChR}$ agonist muscarine, and then we characterized the susceptibility of efferent-mediated slow excitation to the application of the general $\mathrm{mAChR}$ antagonist atropine. 
A

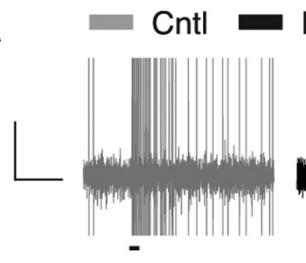

DMPP
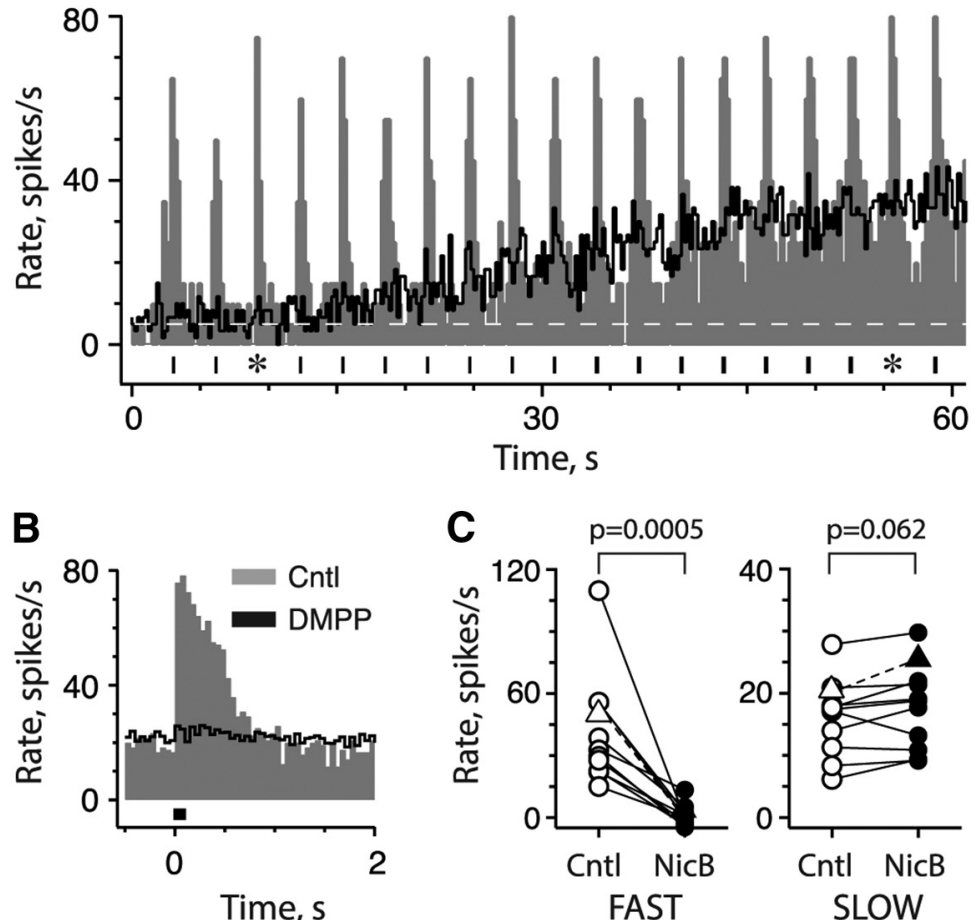
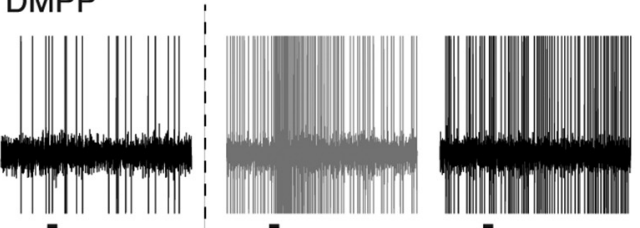

Time, s
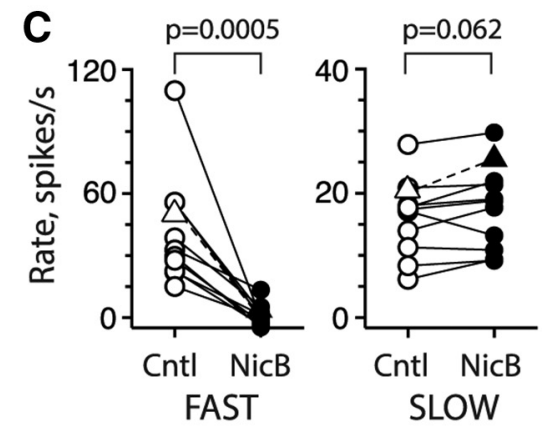

Figure 2. Blockers of efferent-mediated fast excitation do not antagonize efferent-mediated slow excitation. $\boldsymbol{A}$, Bottom, Excitatory responses of $C D$ afferent to repeated short efferent shock trains (black bars, bottom) are shown as a continuous rate histogram before (Cntl, gray bars) and after (black line) $20 \mu \mathrm{m}$ DMPP. Dashed white line, Prestimulus discharge rate. Top, Raw peristimulus spike data, before and after DMPP, at the two time points indicated by asterisks in bottom, respectively. $\boldsymbol{B}$, Perstimulus average response histograms of efferent-mediated fast excitation during control and DMPP conditions were constructed from $A$ data. C, Peak efferent-mediated fast (left) and slow excitation (right) for 10 CD afferents are plotted before (Cntl, open symbols) and after (NicB, filled symbols) the nAChR blockers DMPP, CYT, epibatidine, or TMPH. Triangles with dashed lines represent the units shown in $\boldsymbol{A}$ and $\boldsymbol{B}$.

In the absence of efferent stimulation, the superfusion of 50 or $100 \mu \mathrm{M}$ muscarine excited CD afferents along a similar time course as that seen with efferent-mediated slow excitation, namely taking tens of seconds to develop and decay (Fig. $3 A$ ). During muscarine application in 10 CD units from seven preparations (Fig. 3B, left), there was a significant, nearly fourfold increase in the mean afferent discharge rate, $37.0 \pm 3.2$ spikes $/ \mathrm{s}$, compared with the mean premuscarine discharge rate, $10.7 \pm 1.8$ spikes/s. The mean time-to-peak and duration of muscarinemediated excitation were $64.3 \pm 9.1$ and $187.2 \pm 22.6 \mathrm{~s}$, respectively. It should be noted, however, that 3 of $10 \mathrm{CD}$ afferents from three different preparations did not express an efferent-mediated slow excitation during efferent stimulation. If muscarine- and efferent-mediated slow excitation rely on the same mAChRs, these observations suggested that muscarine, at least in these three CD units, had access to mAChRs not activated by efferent stimulation. This would further suggest that the number of CD afferents expressing efferent-mediated slow excitation in this study may be underestimated due to ineffective efferent stimulus conditions and/or an inability for stimulus-released ACh to reach the same pool of mAChRs.

In 6 of those $10 \mathrm{CD}$ units, the amplitude of efferent-mediated fast excitation was measured before and after muscarine application. Muscarine did not significantly affect efferent-mediated fast excitation (Fig. 3B, right). However, the mean peak amplitude of efferent-mediated slow excitation in four CD units was blocked during muscarine application $(15.6 \pm 3.7$ vs $0.1 \pm 0.5$ spikes $/ \mathrm{s} ; p=0.022$ ). This suggested that muscarine application and efferent-mediated slow excitation were dependent on the same group of mAChRs. We suspected that prolonged exposure to muscarine may have desensitized mAChRs and prevented subsequent activation during efferent stimulation. Similar observations have been seen with efferentmediated fast excitation and nAChR agonists (Fig. 2; Holt et al., 2015b). Finally, we also applied muscarine $(50-100 \mu \mathrm{M})$ to five BT/BM afferents where it failed to mount any discernible response (data not shown). This is consistent with the lack of efferent-mediated slow excitation in these units and with previous evidence that muscarine is not an agonist at $\alpha 9 \mathrm{nAChRs}$ (Verbitsky et al., 2000). These observations provide further evidence that neither $\alpha 4 \alpha 6 \beta 2^{\star}$ nor $\alpha 9^{\star}$ nAChRs are likely to be involved in the generation of efferent-mediated slow excitation.

At a minimum, the muscarine data indicated that CD afferents express mAChRs that are capable of exciting the afferent over an extended time scale. To confirm whether mAChRs are required for the activation of efferent-mediated slow excitation, we used the general $\mathrm{mAChR}$ antagonist atropine $(0.3-10 \mu \mathrm{M})$. In the $\mathrm{CD}$ afferent shown (Fig. $3 C-F$ ), $1 \mu \mathrm{M}$ atropine blocked efferent-mediated slow excitation generated with short (Fig. 3C) and long efferent shock trains (Fig. $3 E$ ), while having little effect on efferent-mediated fast excitation (Fig. 3D,E). These data support the assertion that mAChRs are required for efferent-mediated slow excitation, and that the two efferent stimulation protocols are likely recruiting the same group of receptors. In contrast with the observations with nAChR blockers (Fig. 2C), atropine blocked nearly 94\% of efferentmediated slow excitation $(22.4 \pm 2.3$ vs $1.3 \pm 0.7$ spikes $/ \mathrm{s} ; n=9$; Fig. $3 F$, right) in $\mathrm{CD}$ afferents without significant block of efferent-mediated fast excitation $(34.0 \pm 6.3$ vs $36.2 \pm 6.5$ spikes/s; $n=8$; Fig. $3 F$, left). That atropine concentrations as low as $0.3 \mu \mathrm{M}$ significantly blocked efferent-mediated slow excitation without affecting efferent-mediated fast excitation further supported a role for mAChRs while again excluding $\alpha 4 \alpha 6 \beta 2^{\star} \mathrm{nAChRs}$ and $\alpha 9^{\star} \mathrm{nAChRs}$ (Fuchs and Murrow, 1992; Guth et al., 1994; Verbitsky et al., 2000).

Muscarinic AChR activation enhances afferent sensitivity The pharmacological observations thus far assert that the activation of mAChRs are driving efferent-mediated slow excitation. We were also interested in elucidating what downstream compo- 
A

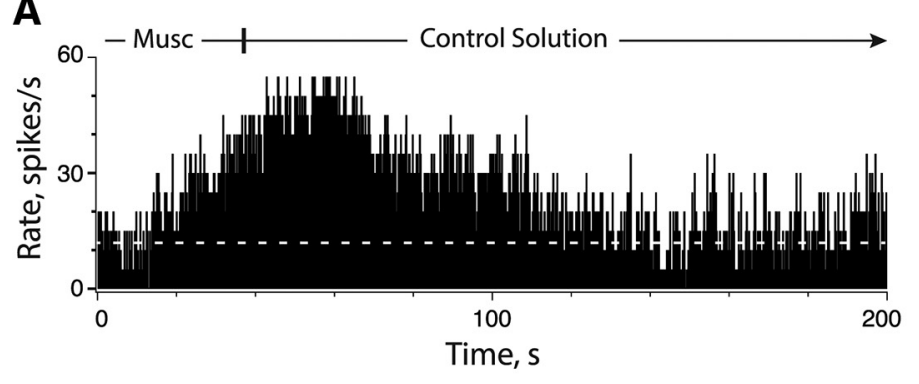

C

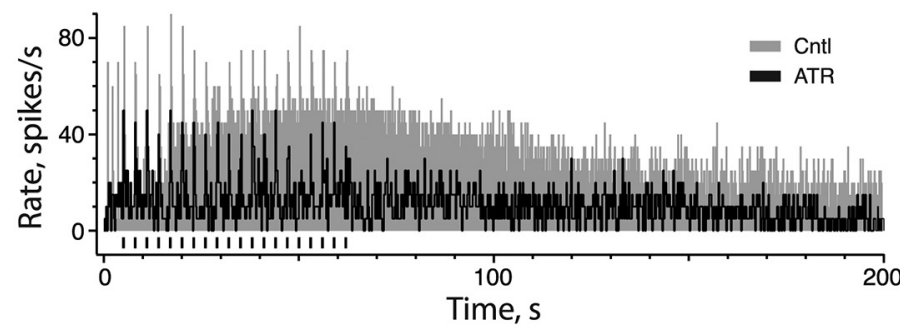

E

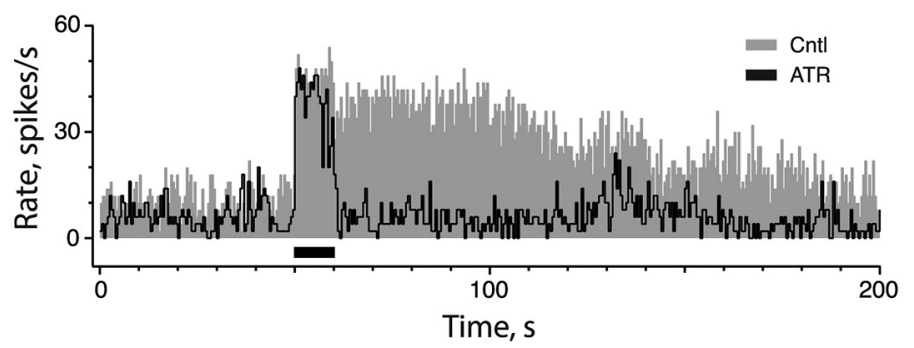

B

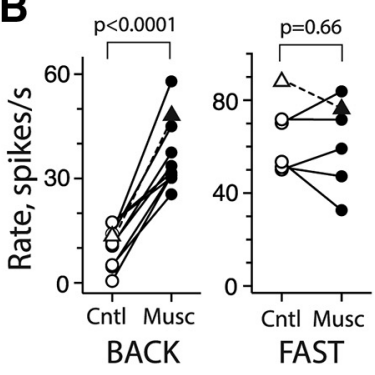

D

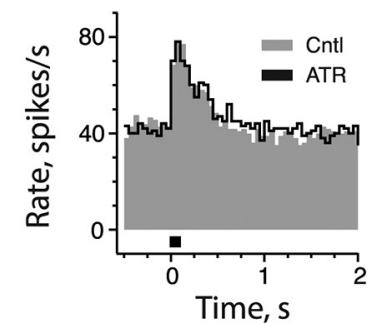

$\mathbf{F}$

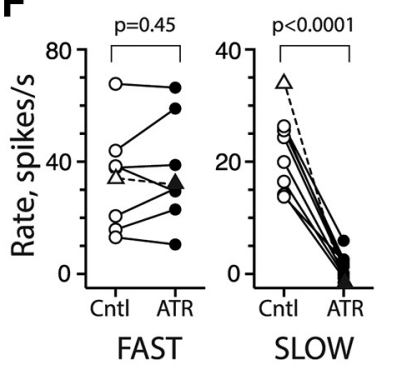

Figure 3. Activation of $m A C h R s$ underlies slow excitation in $C D$ afferents. $A$, Continuous rate histogram was acquired during the application of $50 \mu \mathrm{m}$ muscarine. Dashed white line, Prestimulus discharge rate. $\boldsymbol{B}$, Afferent background rates for nine $(D$ afferents (left, BACK) and peak efferent-mediated fast excitation in six CD afferents (right, FAST) are plotted before (Cntl; open symbols) and after muscarine (Musc; filled symbols) administration. C, Continuous rate histogram from CD afferent to 20 presentations of short efferent shock train (20 shocks at 200/s; black bars) before and after administration of $1 \mu \mathrm{m}$ atropine. Excitatory bursts in $\alpha$ period $(t=0-5 \mathrm{~s}$ ) were unrelated to efferent stimulus, did not persist beyond the $\alpha$ period, and were absent from subsequent recordings in this unit. $\boldsymbol{D}$, Corresponding average response histograms for efferent-mediated fast excitation during control conditions and atropine application were constructed from data in $\boldsymbol{C}$. Histograms were aligned by shifting the atropine trace to match the mean prestimulus rate of the control (14.1 vs $46.1 \mathrm{spikes} / \mathrm{s}$ ). $\boldsymbol{E}$, Continuous rate histogram from same CD afferent during a 10 s efferent shock train (1000 shocks at $100 / s)$ before and after administration of $1 \mu \mathrm{m}$ atropine. $\boldsymbol{F}$, Peak efferent-mediated fast excitation (left) for eight $C D$ afferents and peak slow excitation (right) for nine $C D$ afferents are plotted before (Cntl; open symbols) and after application of atropine (ATR; filled symbols). Triangles with dashed lines in $\boldsymbol{B}$ and $\boldsymbol{F}$ represent units shown in $\boldsymbol{A}$ and $\boldsymbol{C}$, respectively.

nents were involved in the generation of slow excitation. It is well known that the activation of $\mathrm{mAChRs}$ is tied to the regulation of a large number of ion channel candidates that may also be targeted by $m A C h R$ activation in the vestibular periphery (Brown et al., 1997; Brown, 2010). We gained further insight into potential downstream mechanisms in $\mathrm{CD}$ afferents while combining efferent stimulation with vestibular stimulation.

Previous studies have shown that vestibular efferent stimulation can be associated with a reduction or enhancement in afferent sensitivity to concomitant vestibular stimulation (Goldberg and Fernández, 1980; Rossi et al., 1980; Boyle and Highstein, 1990; McCue and Guinan, 1994; Holt et al., 2011; Chagnaud et al., 2015). In this study, we took advantage of the long shock train protocol because it allowed sufficient temporal dispersion between efferent-mediated fast and slow excitation such that we could study the effects of efferent-mediated slow excitation in isolation. We compared the response characteristics of $\mathrm{CD}$ afferents to sinusoidal indentation before and during efferentmediated slow excitation (Fig. 4A). Afferent gain, defined as the peak-to-peak modulation of discharge rate per indenter displacement (in micrometers), was enhanced during efferent-mediated slow excitation compared with control values before efferent stimulation (Fig. 4A,B). In 12 units from 12 preparations, sine wave fits of 12 to 18 individual cycles during control and slow excitation were used to calculate response amplitude and phase during indentation on a cycle-by-cycle basis. Individual gains and phases were each subjected to repeated measures two-way ANOVA with the factors cycle number and the presence/absence of efferent-mediated slow excitation (Fig. 4C). Efferent-mediated slow excitation significantly increased the mean gain from $0.98 \pm$ 0.15 to $1.49 \pm 0.20$ spikes $/ \mathrm{s} \times \mu \mathrm{m}^{-1}\left(F_{(1,145)}=168.3, p<\right.$ $0.0001)$. The mean response phase during control and slow excitation was $36.4 \pm 3.3^{\circ}$ and $42.2 \pm 3.6^{\circ}$, respectively, but this was not significant $\left(F_{(1,145)}=0.02957, p=0.86\right)$. The mean gain changes corresponded to an increase in the mean peak-to-peak modulation from $24.7 \pm 2.9$ to $37.5 \pm 2.4$ spikes/s. This effect was reversible with estimates of sensitivity returning to near control values as the efferent-mediated slow excitation decayed (Fig. 4B).

A similar analysis of afferent gain and phase were also performed in four $\mathrm{CD}$ units from four preparations following the application of muscarine (Fig. $4 D, E$ ). Compared with control conditions, muscarine-mediated slow excitation also significantly increased the mean afferent gain from $0.99 \pm 0.39$ to $1.60 \pm 0.49 \mathrm{spikes} / \mathrm{s} \times \mu \mathrm{m}^{-1}\left(F_{(1,51)}=83.13, p<0.0001\right)$. However, there was no significant difference in response phases be- 
A

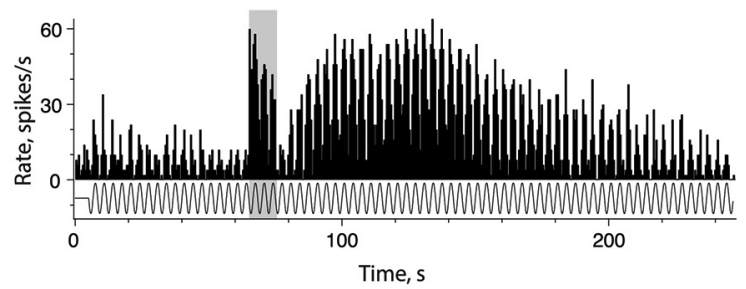

D

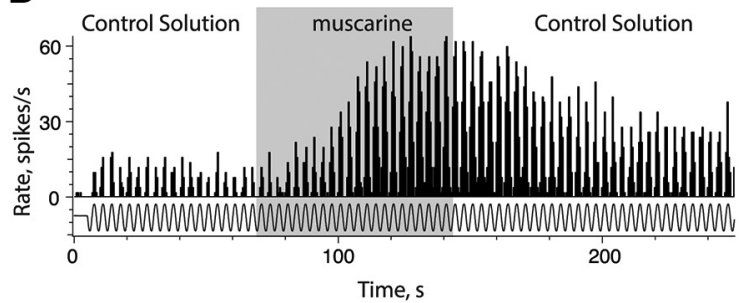

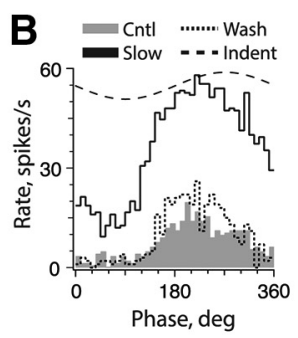

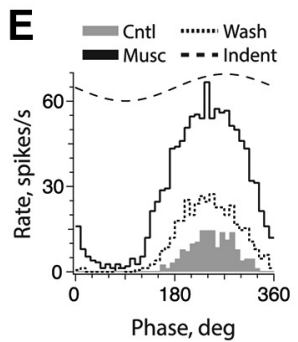

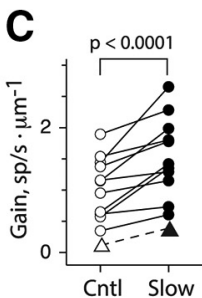

$\mathbf{F}$

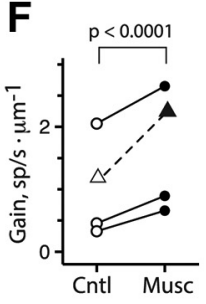

Figure 4. Slow excitation enhances the response of $C D$ afferents to sinusoidal indentation. $A, D$, Continuous rate histograms showing the $C D$ afferent response to the delivery of continuous, fixed-amplitude $0.3 \mathrm{~Hz}$ sinusoidal indentation (along the $x$-axis), before, during, and after a 10 efferent shock train (gray box; $\boldsymbol{A}$ ) or superfusion of $50 \mu \mathrm{m}$ muscarine (gray box; $\boldsymbol{D}$ ). $\boldsymbol{B}, \boldsymbol{E}, \boldsymbol{C}$ orresponding phase histograms were constructed from $\boldsymbol{A}$ and $\boldsymbol{D}$, respectively. Control, slow, and wash traces were generated from the first 18 waves, 18 waves centered on the peak efferent-mediated or muscarine-mediated slow excitation, and 18 waves at record end when discharge rates returned to near control values, respectively. Indent, Fit of indenter displacement signal. $\boldsymbol{C}$, $\boldsymbol{F}$, Corresponding gain measurements in $C D$ afferents, expressed as the average difference in peak-to-peak modulation over indenter amplitude, are shown before (open symbols) and after respective treatments (filled symbols). Triangles and dashed lines represent units shown in $\boldsymbol{B}$ and $\boldsymbol{E}$, respectively.

tween control and during muscarine application $(37.1 \pm 5.7$ vs $\left.35.9 \pm 4.7 ; F_{(1,51)}=0.5332, p=0.47\right)$. The gain changes with muscarine were associated with an increase in the mean peak-topeak modulation rate from $22.3 \pm 5.0$ to $47.6 \pm 6.9$ spikes $/ \mathrm{s}$. Similarities in these data suggest that efferent-mediated slow excitation and muscarine application likely target the same mAChRs that excite CD afferents by closing an ionic conductance normally open under control conditions. The result is an increase in the input impedance of CD afferents, thereby enhancing their subsequent sensitivity to the indenter stimulus. The simplest explanation is that the affected conductance is a potassium channel.

\section{KCNQ and ERG potassium channels are expressed in the turtle canal crista}

Based on our physiological and pharmacological observations, we would predict that these effector potassium channels should be: (1) expressed by most, if not all, CD afferents in the turtle; and (2) localized to regions of the calyx receiving efferent innervation. There are two families of potassium channels, ERG and KCNQ, that have been previously localized to rodent calyx endings (Kharkovets et al., 2000; Hurley et al., 2006; Lysakowski et al., 2011; Spitzmaul et al., 2013). These channels give rise to so-called M-currents given that they are subject to closure by mAChRs (Meves et al., 1999; Lerche et al., 2000; Schroeder et al., 2000; Søgaard et al., 2001; Selyanko et al., 2002; Kubo et al., 2015). We used IHC with previously characterized antibodies against KCNQ3, KCNQ4, and Erg1-3 to identify whether any of these potassium channels are also expressed in $\mathrm{CD}$ afferents in the turtle crista. We also used antibodies to CR to counterstain CD afferents and delineate the central zone (Monk and Peterson, 1995; Huwe et al., 2011; Jordan et al., 2015).

In longitudinal sections of the crista (Fig. $5 \mathrm{~A}$, inset), antibodies to KCNQ4 robustly stained a series of "u-shaped" structures throughout the $\mathrm{CZ}$ (Fig. $5 A$ ), as evidenced by counterstaining for calretinin in the same tissue sections (Fig. 5B). KCNQ4 staining overlapped with CR with the exception of central zone regions adjacent to the planum (Fig. 5B, asterisk) where CR staining of calyceal endings is typically faint (Jordan et al., 2015). In adjacent torus regions, KCNQ4 labeling was occasionally seen in type II hair cells (Fig. 5B, inset, arrows) as well as bouton afferent terminals that appeared unstained for CR (Fig. $5 A, B$, arrowhead). At higher magnification, KCNQ4 labeling was primarily restricted to the lower half of the inner face of the calyx ending (Fig. $5 C$ ), close to the parent axon where clusters of synapsin-positive, efferent varicosities are typically located (Fig. 5D, arrows). This is similar to its location in domain 1 of mammalian calyces (Lysakowski et al., 2011). In oblique sections through the bottom half of calyx afferents, KCNQ4 staining primarily labeled most of the calyceal inner face (Fig. 5E, arrowheads), which is most evident in the internal walls. There were also occasional pockets of KCNQ4 staining on the outer face (Fig. $5 E$, arrows).

Unlike KCNQ4, staining for KCNQ3 was most intense along the apical regions of calyx endings where it also colocalized with CR (Fig. 5F, arrowheads). Small KCNQ3-positive puncta were also occasionally seen along the outer face and calyceal stalk (Fig. $5 F$, arrows). Faint KCNQ3 staining was also observed in type I and II hair cells (Fig. 5F, asterisks).

Staining for ERG1 was found both in type I hair cells (Fig. 5G, asterisks) and the inner face of most calyceal afferents where it appeared to overlap with CR staining (Fig. 5G, arrowhead). Antibodies to ERG2 stained the inner and outer face of CR-positive calyceal endings (Fig. $5 \mathrm{H}$, asterisks) as well as a number of punctate structures throughout the hair cell layer (Fig. $5 \mathrm{H}$, arrowhead). ERG2-positive puncta often colocalized with CR staining, suggesting that some of these structures are afferent bouton terminals (Fig. 5H, arrows). Finally, anti-ERG3 primarily labeled hair cells throughout the crista including type I hair cells in the $\mathrm{CZ}$, type II hair cells in the torus, and type II hair cells in the planum where it overlapped with CR staining (Fig. 5I). There appeared to be some labeling of calyceal endings, but it was difficult to reconcile given the intense staining of type I hair cells (Fig. 5I, arrowheads). 

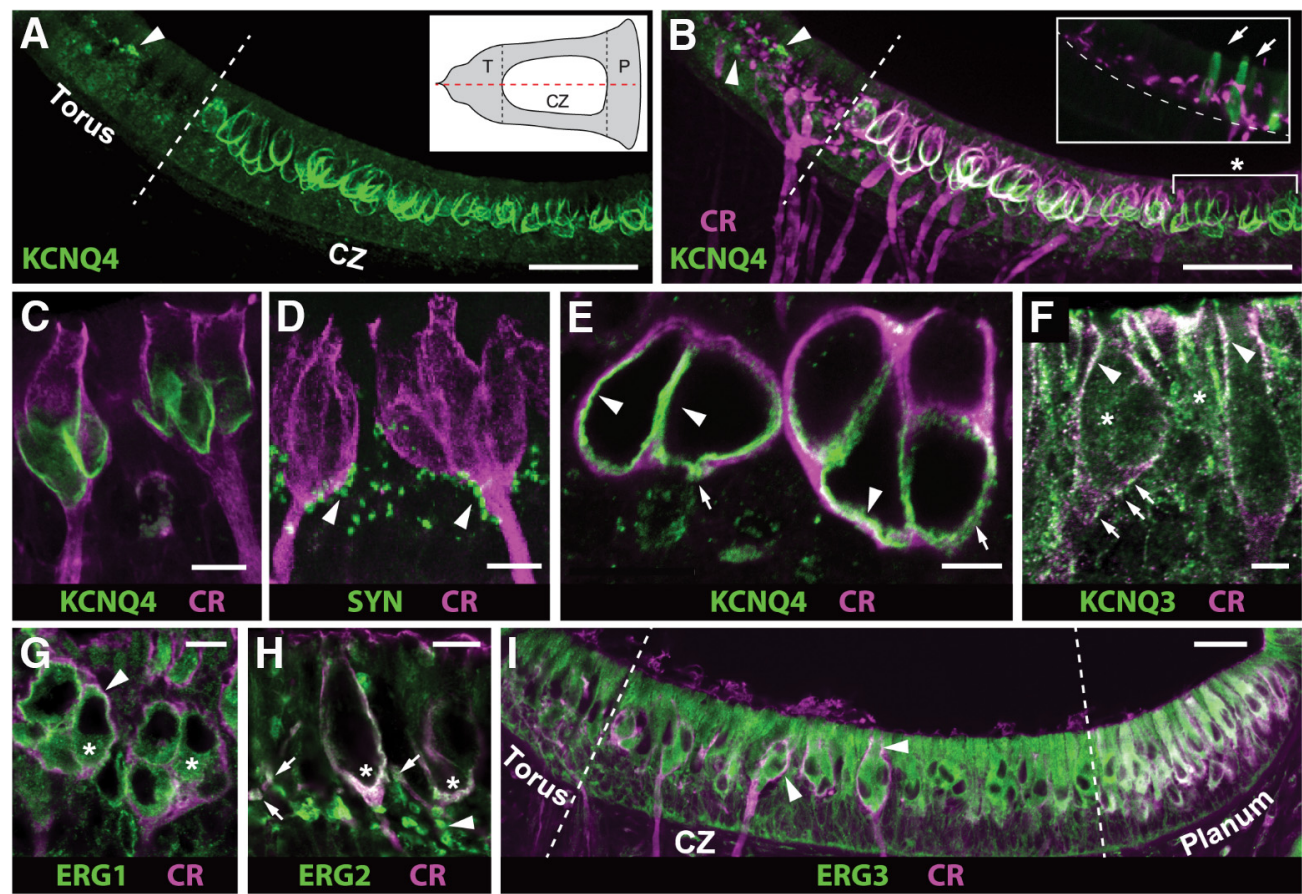

KCNQ4 CR

Figure 5. Immunoreactivities for KCNQ and ERG potassium channel subunits are observed in the turtle crista. $A, B$, Confocal image projection of a longitudinal section of turtle crista stained with antibodies against KCNQ4 subunit (green) and CR (magenta). White dashed line demarcates boundary between the torus and CZ. Arrowheads point to KCNQ4-positive afferent bouton terminals. Asterisk in $\boldsymbol{B}$ identifies group of $C D$ afferents where CR staining is less intense or absent. $\boldsymbol{A}$, Inset, Schematic of turtle hemicrista showing general plane of tissue section (red dashes) and zonal boundaries (black dashes) where T and P label the torus and planum, respectively. $\boldsymbol{B}$, Inset, Confocal image projection of longitudinal section of the torus from another turtle crista stained with antibodies against KCNQ4 (green) and CR (magenta). CR stains bouton terminals and arrows demarcate KCNQ4-positive type Il hair cells. Dashed line demarcates the natural curvature of the torus basement membrane. $\boldsymbol{C}$, Intermediate magnification of two $\mathrm{CR}^{+}$calyx afferents (magenta) stained with anti-KCNQ4 (green). $\boldsymbol{D}$, In this confocal image projection, calyx afferents and presynaptic compartment of efferent varicosities were stained with antibodies to $C R$ (magenta) and synapsin (SYN; green) respectively. Arrowheads identify clusters of efferent contacts along calyceal stalk and outer face. $\boldsymbol{E}$, Oblique section through the base of two complex calyx afferents reveals the extent of overlap of CR (magenta) and KCNQ4 (green). Arrowheads point to KCNQ4 staining along the inner face, while arrows indicate pockets of KCNQ4 staining on the outer face. $\boldsymbol{F}$, High-magnification image of two calyx afferents, from the CZ bordering the planum, immunolabeled with CR (magenta) and KCNQ3 (green). Arrowheads indicate colocalization, while arrows identify KCNQ3 puncta along the calyceal base. Asterisks demarcate possible hair cell staining. G, 0 blique section through the bases of two complex calyx afferents reveals the extent of overlap of CR (magenta) and Erg1 (green). Arrowhead indicates the colocalization of CR and Erg1, while asterisks indicate some anti-Erg1 staining in type I hair cells. $\boldsymbol{H}$, High-magnification image of two $\mathrm{CR}^{+}$calyx afferents (magenta) and immunohistochemical labeling of Erg2 (green). The arrowhead specifies Erg2-positive puncta, while arrows show colocalization with CR-positive afferent bouton terminals. Asterisks highlight calyceal colocalization of CR and Erg2. $I$, Confocal image projection of the longitudinal section of turtle crista stained with antibodies against Erg3 subunit (green) and CR (magenta). The arrowheads are possible colocalization of Erg3 and CR in several calyx endings. Scale bars: $\boldsymbol{A}, \boldsymbol{B}, 50 \mu \mathrm{m}$; $C, D, G, H, 10 \mu \mathrm{m} ; E, F, 5 \mu \mathrm{m} ; I, 20 \mu \mathrm{m}$.

\section{Efferent-mediated slow excitation in CD afferents requires KCNQ potassium channels}

Of the potassium channel candidates probed in our IHC experiments, the staining patterns of KCNQ subunits, particularly KCNQ4, were most closely matched to our physiological observations and our predictions about the presumed location of the effector potassium channels targeted during efferent-mediated slow excitation. The involvement of KCNQ channels may be distinguished pharmacologically from ERG channels on the basis of their differential sensitivity to XE991. When administered at concentrations of $\leq 10 \mu \mathrm{M}$, XE991 potently antagonizes KCNQ channels while contributing to $\leq 5 \%$ to the blockade of ERG channels (Elmedyb et al., 2007; Pérez et al., 2009). To investigate the role of KCNQ channels in the development of efferentmediated slow excitation, we tested whether XE991 (1-10 $\mu \mathrm{M})$ would, in fact, block efferent-mediated slow excitation. In the example shown, efferent-mediated fast and slow excitation were generated using 20 short efferent shock trains (Fig. 6A). The addition of $10 \mu \mathrm{M}$ XE991 increased background discharge and simultaneously antagonized efferent-mediated slow excitation (Fig. 6B). The loss of efferent-mediated slow excitation likely does not represent a ceiling effect as efferent-mediated fast excitation remains intact and unaffected by XE991 (Fig. 6B,C). We applied XE991 to a total of $10 \mathrm{CD}$ units from 10 preparations and characterized its effects on afferent background discharge rates, efferent-mediated fast and slow excitation, and/or afferent sensitivity to sinusoidal indentation. XE991 increased the mean background discharge rate by $17.8 \pm 2.4$ spikes/s $(n=10)$. In eight units, efferent-mediated fast excitation was not significantly different between control conditions and during XE991 application (45.2 \pm 6.1 vs $44.4 \pm 5.6$ spikes/s; Fig. $6 D$, left), while mean efferent-mediated slow excitation in six units was significantly blocked (18.0 \pm 3.1 vs $0.2 \pm 0.7$; Fig. $6 D$, right). Finally, consistent with our observations with efferent-mediated slow excitation and muscarine application, XE991 significantly enhanced the response of $\mathrm{CD}$ afferents to sinusoidal indentation by increasing the peak-to-peak modulation rate from $13.5 \pm 2.7$ to $30.8 \pm$ 1.3 spikes/s $\left(F_{(1,52)}=235.8, p<0.0001\right)$.

\section{Discussion}

Slow excitation of vestibular afferents, during efferent stimulation or the application of cholinergic agonists, has been observed in many studies (Guth et al., 1998; Holt et al., 2011). Despite similarities in afferent responses under the two experimental conditions, there was no direct evidence that ACh underlies slow responses during EVS stimulation. Here, we established, for the first time, that efferent-mediated slow excitation enhances the sensitivity of turtle CD afferents by activating $\mathrm{mAChR}$ and clos- 
A

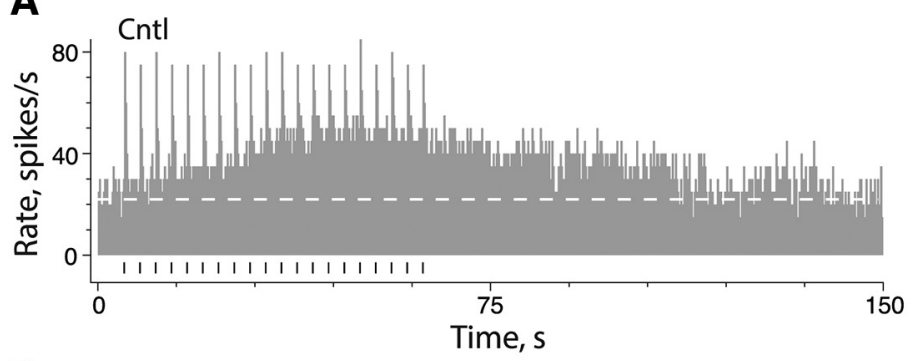

B

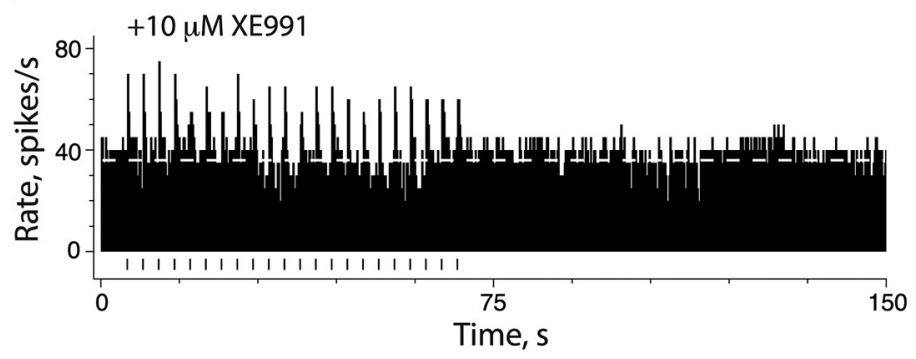

C

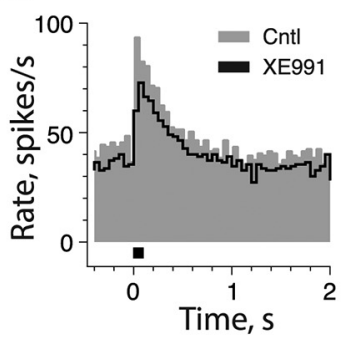

D

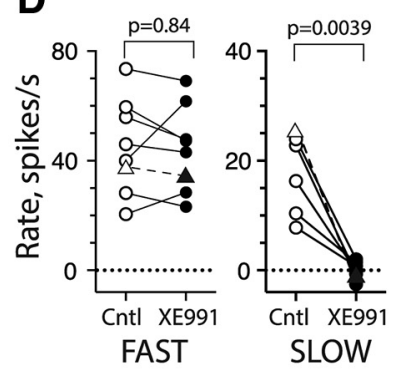

Figure 6. Efferent-mediated slow excitation requires KCNQ channels. $A, B$, Excitatory responses of CD afferent to short efferent shock trains (20 shocks at 200/s; black bars, $n=20)$ are shown as continuous rate histograms before $(\boldsymbol{A})$ and after $(\boldsymbol{B}) 10 \mu \mathrm{m}$ XE991. C, Corresponding average response histograms for efferent-mediated fast excitation during control and XE991 were constructed from data in $\boldsymbol{A}$ and $\boldsymbol{B}$, respectively. $\boldsymbol{D}$, Peak efferent-mediated fast excitation (left, $n=8$ ) and peak slow excitation (right, $n=6$ ) in CD afferents are plotted before (Cntl; open symbols) and after (filled symbols) the administration of XE991. Triangles and dashed lines represent units shown in $\boldsymbol{A}$ and $\boldsymbol{B}$.

ing KCNQ potassium channels in calyceal endings. These findings prompt further discussion of mAChRs and KCNQ channels in efferent neurotransmission, offer insight into EVS function, and might provide an additional rationale for the clinical use of $\mathrm{mAChR}$ antagonists to treat vestibular dysfunction.

\section{Roles of mAChRs in the response of vestibular afferents to efferent stimulation}

RT-PCR and immunohistochemistry suggest that all five $\mathrm{mAChR}$ subtypes are expressed in vestibular neuroepithelia (Wackym et al., 1996; Li et al., 2007). Furthermore, pharmacological studies have proposed several mechanisms by which mAChRs modulate hair cell transmitter release and afferent excitability (Bernard et al., 1985; Ohtani et al., 1994; Holt et al., 2003; Derbenev et al., 2005; Li and Correia, 2011; Guo et al., 2012). Are the mechanisms of efferent-mediated slow excitation in turtle CD afferents applicable to other species and/or afferent classes? Pharmacological data in rodents suggest that efferent-mediated slow excitation of mammalian calyx-bearing afferents also involves the activation of odd-numbered mAChRs and the closure of KCNQ channels (Pérez et al., 2009; Holt et al., 2015a). We and others have also reported that efferent-mediated slow excitation is occasionally seen in turtle bouton afferents, which might provide insight into efferentmediated slow excitation of mammalian bouton afferents (Goldberg and Fernández, 1980; Brichta and Goldberg, 2000b; Marlinski et al., 2004). Our immunohistochemical data in turtle and pharmacological data in birds (Rennie et al., 2001) suggest that type II hair cells and bouton terminals express KCNQ channels. We would predict that KCNQ closure in either location would enhance afferent excitability, but the lack of pharmacological data in either species prevents confirming whether efferent-mediated slow excitation of bouton afferents also uses an M-current mechanism.

In amphibians, that lack type I hair cells and calyceal afferents, mAChR-mediated slow excitation of vestibular afferents appears to rely on activation of odd-numbered mAChRs on type II hair cells that enhance transmitter release, not through KCNQ closure, but through elevation of intracellular calcium or direct in- teractions with the synaptic machinery (Bobbin et al., 1985; Holt et al., 2003; Derbenev et al., 2005). There is evidence that M2$\mathrm{mAChRs}$ activate BK potassium channels in mammalian type II hair cells (Guo et al., 2012), but we saw no efferent-mediated or muscarine-activated responses in turtle afferents consistent with this mechanism. However, if M2mAChR-BK signaling exists in the turtle and evolved within the same temporal envelope as efferent-mediated slow excitation, the application of muscarine or atropine would have not been useful in separating the two phenomena. Identifying the subtypes underlying these various forms of efferent-mediated slow excitation in any species requires using selective mAChR ligands and/or exploring the phenomenon in mAChR knock-out animals.

\section{Efferent targeting of KCNQ channels}

M-current members include the ERG and KCNQ families (Meves et al., 1999; Lerche et al., 2000; Schroeder et al., 2000; Søgaard et al., 2001; Selyanko et al., 2002; Kubo et al., 2015). Our immunohistochemistry findings suggest that turtle cristae express ERG1-3, KCNQ3, and KCNQ4 potassium channels, paralleling observations in mammals (Kharkovets et al., 2000; Hurley et al., 2006; Lysakowski et al., 2011; Spitzmaul et al., 2013). KCNQ2 and KCNQ5, expressed on the calyceal inner face in rodents (Hurley et al., 2006; Lysakowski et al., 2011), remain to be identified in turtles. KCNQ channels were favored as follows: (1) distribution of KCNQ immunoreactivity coincides with our physiological data that efferent-mediated slow excitation occurs primarily in CD afferents; (2) efferent-mediated slow excitation was completely blocked by XE991 at concentrations that minimally antagonize ERG channels (Elmedyb et al., 2007; Pérez et al., 2009); (3) KCNQ blockers increase quantal size with little effect on type I hair cell conductances, consistent with KCNQ blockade in calyces (Hurley et al., 2006; Holt et al., 2007; Spitzmaul et al., 2013); and (4) unlike XE991, the ERG blocker E4031 did not affect vestibular neuronal excitability (Holt et al., 2007; Pérez et al., 2009). However, we cannot completely dismiss ERG channels as they colocalize and can form functional, macromolecular 
complexes with KCNQ (Hurley et al., 2006; Ren et al., 2010; Guo et al., 2011; Lysakowski et al., 2011; Abriel et al., 2015) and could contribute to efferent-mediated slow excitation.

Odd-numbered mAChRs close KCNQ channels through PLC activation and depletion of membranal phosphatidylinositol4,5-bisphosphate (PIP2), whose presence keeps KCNQ channels open (Brown and Passmore, 2009; Pérez et al., 2010). Efferent varicosities on $\mathrm{CD}$ afferents suggest that $\mathrm{mAChRs}$ would localize to the stalk and outer face (Jordan et al., 2015). PLC activation is membrane delimited (Falkenburger et al., 2010; Duc et al., 2015) and suggests that the affected KCNQ channels are also expressed in the outer face. While consistent with our KCNQ3 immunoreactivity, could outer face $\mathrm{mAChRs}$ also close KCNQ4-containing channels on the inner face? Calmodulin (CaM) is constitutively bound to KCNQ channels (Gamper and Shapiro, 2003). During elevated intracellular calcium concentrations, conformational changes in the CaM-KCNQ complex reduce the affinity of KCNQ for PIP2, resulting in current suppression (Chambard and Ashmore, 2005; Kosenko and Hoshi, 2013; Sihn et al., 2016). This mechanism could tie outer-face $\mathrm{mAChR}$ activation with the closure of inner-face KCNQ channels.

\section{Functional considerations}

What is the functional significance of having both fast and slow efferent-mediated excitation? Stimulation paradigms used in this study relied on high shock train frequencies $(>100 \mathrm{~Hz})$ to elicit large-amplitude efferent-mediated fast and slow excitation within a single trial. However, it should be noted that both mechanisms can be recruited at shock frequencies as low as $20 \mathrm{~Hz}$ (Goldberg and Fernández, 1980; Brichta and Goldberg, 2000b), which is easily within reported EVS discharge rates (Roberts and Russell, 1972; Highstein and Baker, 1985). Given their response kinetics, efferent-mediated fast excitation could modify peripheral vestibular function transiently while slow excitation might provide more long-term control. In this context, efferent-mediated slow excitation might enhance afferent sensitivity as part of an arousal system. Anatomical data indicate that EVS neurons receive significant input from the reticular formation, a major arousal system hub (Pfaff et al., 2005; Metts et al., 2006). Furthermore, several studies have implicated the EVS as a mechanism by which an enhancement of afferent sensitivity might be warranted during arousal state changes like sleep-to-awake transitions or postural threats (Horslen et al., 2014; Naranjo et al., 2015; Schwarz et al., 2015; Lim et al., 2016).

We have known for some time that EVS stimulation modifies afferent sensitivity to ongoing vestibular stimulation in several vertebrates (Goldberg and Fernández, 1980; Rossi et al., 1980; Boyle and Highstein, 1990; Chagnaud et al., 2015). In fish and amphibians, efferent-mediated fast inhibition or excitation attenuates afferent responsiveness during self-generated movements (Boyle and Highstein, 1990; Chagnaud et al., 2015), but the evidence for similar attenuation in mammals has been less compelling (Cullen and Minor, 2002; Sadeghi et al., 2007b; Jamali et al., 2009). Recent studies in mice have indicated that the EVS modulates the amplitude of the vestibulo-ocular reflex (VOR) and vestibular stimulus-evoked potentials (Luebke et al., 2014; Hübner et al., 2015; Morley et al., 2016). While efferent-mediated fast inhibition or fast excitation may attenuate vestibular input (Boyle and Highstein, 1990; Chagnaud et al., 2015; Hübner et al., 2015), our data suggest that mAChRs and KCNQ closure could provide the EVS with a counter mechanism to enhance vestibular input. The EVS may also alter afferent discharge regularity, action potential kinetics, and information transfer by modulating po- tassium channels and/or nAChRs in hair cells and afferents (Han et al., 2007; Pérez et al., 2009; Kalluri et al., 2010; Meredith and Rennie, 2015; Contini et al., 2016). This in turn may modify coding schemes to adjust how phasic and tonic pathways sense head movements and drive vestibular behaviors like the VOR (Sadeghi et al., 2007a; Hübner et al., 2015; Morley et al., 2016).

\section{Clinical implications}

These data have important implications for revisiting vestibular maladies where $\mathrm{mAChR}$ antagonists have proven to be effective. The anti-muscarinic agents atropine, scopolamine, glycopyrrolate, and zamifenacin alleviate motion sickness and some symptoms of Ménière's disease (Golding and Stott, 1997; Storper et al., 1998; Yates et al., 1998; Huppert et al., 2011). The prevailing hypothesis suggests that motion sickness develops when vestibular, visual, and/or proprioceptive inputs, regarding body position in space, are in conflict with internal expectations (Yates et al., 1998; Bertolini and Straumann, 2016). Clinical effectiveness of anti-muscarinic agents may stem from mAChR blockade within the vestibular nuclei that receive many of the above sensory inputs (Yates et al., 1998; Cullen, 2012). Our data indicate that we must also consider peripheral mAChR activation, which may contribute to or exaggerate the sensory conflict by exciting vestibular afferents and/or enhancing their sensitivity to subsequent vestibular stimuli. Targeting odd-numbered $\mathrm{mAChRs}$ and KCNQ channels in the ear using selective antagonists and activators, respectively, could ameliorate symptoms of motion sickness while avoiding centrally mediated side effects. Interestingly, glycopyrrolate may already work in this capacity given that it poorly penetrates the blood-brain barrier (Proakis and Harris, 1978; Mirakhur and Dundee, 1983).

\section{References}

Abriel H, Rougier JS, Jalife J (2015) Ion channel macromolecular complexes in cardiomyocytes: roles in sudden cardiac death. Circ Res 116:19711988. CrossRef Medline

Aubert A, Norris CH, Guth PS (1994) Influence of ATP and ATP agonists on the physiology of the isolated semicircular canal of the frog (Rana pipiens). Neuroscience 62:963-974. CrossRef Medline

Bailey GP, Sewell WF (2000) Pharmacological characterization of the CGRP receptor in the lateral line organ of Xenopus laevis. J Assoc Res Otolaryngol 1:82-88. CrossRef Medline

Bergeron AL, Schrader A, Yang D, Osman AA, Simmons DD (2005) The final stage of cholinergic differentiation occurs below inner hair cells during development of the rodent cochlea. J Assoc Res Otolaryngol 6:401415. CrossRef

Bernard C, Cochran SL, Precht W (1985) Presynaptic actions of cholinergic agents upon the hair cell-afferent fiber synapse in the vestibular labyrinth of the frog. Brain Res 338:225-236. CrossRef Medline

Bertolini G, Straumann D (2016) Moving in a moving world: a review on vestibular motion sickness. Front Neurol 7:14. CrossRef Medline

Bobbin RP, Bledsoe SC Jr, Winbery S, Ceasar G, Jenison GL (1985) Comparative actions of GABA and acetylcholine on the Xenopus laevis lateral line. Comp Biochem Physiol C 80:313-318. CrossRef Medline

Boyle R, Highstein SM (1990) Efferent vestibular system in the toadfish: action upon horizontal semicircular canal afferents. J Neurosci 10:15701582. Medline

Boyle R, Rabbitt RD, Highstein SM (2009) Efferent control of hair cell and afferent responses in the semicircular canals. J Neurophysiol 102:15131525. CrossRef Medline

Brichta AM, Goldberg JM (2000a) Morphological identification of physiologically characterized afferents innervating the turtle posterior crista. J Neurophysiol 83:1202-1223. Medline

Brichta AM, Goldberg JM (2000b) Responses to efferent activation and excitatory response-intensity relations of turtle posterior-crista afferents. J Neurophysiol 83:1224-1242. Medline

Brichta AM, Peterson EH (1994) Functional architecture of vestibular pri- 
mary afferents from the posterior semicircular canal of a turtle, Pseudemys (Trachemys) scripta elegans. J Comp Neurol 344:481-507. CrossRef

Bridgeman D, Hoffman L, Wackym PA, Micevych PE, Popper P (1996) Distribution of choline acetyltransferase mRNA in the efferent vestibular neurons of the chinchilla. J Vestib Res 6:203-212. CrossRef Medline

Brown DA (2010) Muscarinic acetylcholine receptors (mAChRs) in the nervous system: some functions and mechanisms. J Mol Neurosci 41: 340-346. CrossRef Medline

Brown DA, Passmore GM (2009) Neural KCNQ (Kv7) channels. Br J Pharmacol 156:1185-1195. CrossRef Medline

Brown DA, Abogadie FC, Allen TG, Buckley NJ, Caulfield MP, Delmas P, Haley JE, Lamas JA, Selyanko AA (1997) Muscarinic mechanisms in nerve cells. Life Sci 60:1137-1144. CrossRef Medline

Castellano-Muñoz M, Israel SH, Hudspeth AJ (2010) Efferent control of the electrical and mechanical properties of hair cells in the bullfrog's sacculus. PLoS One 5:e13777. CrossRef Medline

Chagnaud BP, Banchi R, Simmers J, Straka H (2015) Spinal corollary discharge modulates motion sensing during vertebrate locomotion. Nat Commun 6:7982. CrossRef Medline

Chambard JM, Ashmore JF (2005) Regulation of the voltage-gated potassium channel KCNQ4 in the auditory pathway. Pflugers Arch 450:34-44. CrossRef Medline

Contini D, Price SD, Art JJ (2016) Accumulation of K+ in the synaptic cleft modulates activity by influencing both vestibular hair cell and calyx afferent in the turtle. J Physiol. Advance online publication. Retrieved January 18, 2017. doi:10.1113/JP273060. CrossRef

Cullen KE (2012) The vestibular system: multimodal integration and encoding of self-motion for motor control. Trends Neurosci 35:185-196. CrossRef Medline

Cullen KE, Minor LB (2002) Semicircular canal afferents similarly encode active and passive head-on-body rotations: implications for the role of vestibular efference. J Neurosci 22:RC226. Medline

Derbenev AV, Linn CL, Guth PS (2005) Muscarinic ACh receptor activation causes transmitter release from isolated frog vestibular hair cells. J Neurophysiol 94:3134-3142. CrossRef Medline

Dickman JD, Correia MJ (1989) Responses of pigeon horizontal semicircular canal afferent fibers. I. Step, trapezoid, and low-frequency sinusoid mechanical and rotational stimulation. J Neurophysiol 62:1090-1101. Medline

Duc NM, Kim HR, Chung KY (2015) Structural mechanism of G protein activation by G protein-coupled receptor. Eur J Pharmacol 763:214-222. CrossRef Medline

Elmedyb P, Calloe K, Schmitt N, Hansen RS, Grunnet M, Olesen SP (2007) Modulation of ERG channels by XE991. Basic Clin Pharmacol Toxicol 100:316-322. CrossRef Medline

Falkenburger BH, Jensen JB, Dickson EJ, Suh BC, Hille B (2010) Phosphoinositides: lipid regulators of membrane proteins. J Physiol 588:31793185. CrossRef Medline

Fuchs PA, Murrow BW (1992) A novel cholinergic receptor mediates inhibition of chick cochlear hair cells. Proc Biol Sci 248:35-40. CrossRef Medline

Gamper N, Shapiro MS (2003) Calmodulin mediates Ca2+-dependent modulation of M-type K+ channels. J Gen Physiol 122:17-31. CrossRef Medline

Goldberg JM, Fernández C (1980) Efferent vestibular system in the squirrel monkey: anatomical location and influence on afferent activity. J Neurophysiol 43:986-1025. Medline

Golding JF, Stott JR (1997) Comparison of the effects of a selective muscarinic receptor antagonist and hyoscine (scopolamine) on motion sickness, skin conductance and heart rate. Br J Clin Pharmacol 43:633-637. CrossRef Medline

Guo CK, Wang Y, Zhou T, Yu H, Zhang WJ, Kong WJ (2012) M2 muscarinic $\mathrm{ACh}$ receptors sensitive $\mathrm{BK}$ channels mediate cholinergic inhibition of type II vestibular hair cells. Hear Res 285:13-19. CrossRef Medline

Guo J, Wang T, Yang T, Xu J, Li W, Fridman MD, Fisher JT, Zhang S (2011) Interaction between the cardiac rapidly (IKr) and slowly (IKs) activating delayed rectifier potassium channels revealed by low $\mathrm{K}+$-induced $\mathrm{hERG}$ endocytic degradation. J Biol Chem 286:34664-34674. CrossRef Medline

Guth PS, Dunn A, Kronomer K, Norris CH (1994) The cholinergic pharmacology of the frog saccule. Hear Res 75:225-232. CrossRef Medline

Guth PS, Perin P, Norris CH, Valli P (1998) The vestibular hair cells: post- transductional signal processing. Prog Neurobiol 54:193-247. CrossRef Medline

Guth PS, Holt JC, Lioudyno M, McIntosh JM, Hendricson AW, Athas GB, Shipon S (2002) The pharmacology of the non- $\alpha 9 \alpha 10$ nicotinic receptor of hair cells: clues as to subunit composition. Abstract presented at 25th Annual MidWinter Meeting, Association for Research in Otolaryngology, Daytona Beach, FL, February.

Haghighi AP, Cooper E (1998) Neuronal nicotinic acetylcholine receptors are blocked by intracellular spermine in a voltage-dependent manner. J Neurosci 18:4050-4062. Medline

Han GC, Lasker DM, Vetter DE, Minor LB (2007) Extracellular recordings from semicircular canal afferents in mice that lack the alpha 9 acetylcholine receptor subunit. Abstract presented at 30th Annual MidWinter Meeting, Association for Research in Otolaryngology, Baltimore, MD, February.

Highstein SM, Baker R (1985) Action of the efferent vestibular system on primary afferents in the toadfish, Opsanus tau. J Neurophysiol 54:370 384. Medline

Holstein GR, Martinelli GP, Nicolae RA, Rosenthal TM, Friedrich VL Jr (2005) Synapsin-like immunoreactivity is present in hair cells and efferent terminals of the toadfish crista ampullaris. Exp Brain Res 162:287292. CrossRef Medline

Holt JC, Lioudyno M, Athas G, Garcia MM, Perin P, Guth PS (2001) The effect of proteolytic enzymes on the alpha9-nicotinic receptor-mediated response in isolated frog vestibular hair cells. Hear Res 152:25-42. CrossRef Medline

Holt JC, Lioudyno M, Guth PS (2003) A pharmacologically distinct nicotinic ACh receptor is found in a subset of frog semicircular canal hair cells. J Neurophysiol 90:1526-1536. CrossRef Medline

Holt JC, Lysakowski A, Goldberg JM (2006a) Mechanisms of efferentmediated responses in the turtle posterior crista. J Neurosci 26:1318013193. CrossRef Medline

Holt JC, Xue JT, Brichta AM, Goldberg JM (2006b) Transmission between type II hair cells and bouton afferents in the turtle posterior crista. J Neurophysiol 95:428-452. CrossRef Medline

Holt JC, Chatlani S, Lysakowski A, Goldberg JM (2007) Quantal and nonquantal transmission in calyx-bearing fibers of the turtle posterior crista. J Neurophysiol 98:1083-1101. CrossRef Medline

Holt JC, Lysakowski A, Goldberg JM (2011) Efferent vestibular system. In: Auditory and vestibular efferents (Ryugo DK, Fay RR, Popper AN, eds), pp 135-186. New York: Springer.

Holt JC, Jordan P, Schneider G (2015a) Pharmacological characterization of the synaptic mechanisms governing the responses of mammalian vestibular afferents to efferent stimulation. Abstract presented at 38th Annual MidWinter Meeting, Association for Research in Otolaryngology, Baltimore, MD, February.

Holt JC, Kewin K, Jordan PM, Cameron P, Klapczynski M, McIntosh JM, Crooks PA, Dwoskin LP, Lysakowski A (2015b) Pharmacologically distinct nicotinic acetylcholine receptors drive efferent-mediated excitation in calyx-bearing vestibular afferents. J Neurosci 35:3625-3643. CrossRef Medline

Horslen BC, Dakin CJ, Inglis JT, Blouin JS, Carpenter MG (2014) Modulation of human vestibular reflexes with increased postural threat. J Physio 592:3671-3685. CrossRef Medline

Hübner PP, Khan SI, Migliaccio AA (2015) The mammalian efferent vestibular system plays a crucial role in the high-frequency response and short-term adaptation of the vestibuloocular reflex. J Neurophysiol 114:3154-3165. CrossRef Medline

Huppert D, Strupp M, Mückter H, Brandt T (2011) Which medication do I need to manage dizzy patients? Acta Otolaryngol 131:228-241. CrossRef Medline

Hurley KM, Gaboyard S, Zhong M, Price SD, Wooltorton JR, Lysakowski A, Eatock RA (2006) M-like K+ currents in type I hair cells and calyx afferent endings of the developing rat utricle. J Neurosci 26:10253-10269. CrossRef Medline

Huwe J, Williams B, Rowe M, Peterson E (2011) Afferent terminal arbor structure in turtle utricle. Abstract presented at 34th Annual MidWinter Meeting, Association for Research in Otolaryngology, Denver, CO, February.

Jamali M, Sadeghi SG, Cullen KE (2009) Response of vestibular nerve afferents innervating utricle and saccule during passive and active translations. J Neurophysiol 101:141-149. CrossRef Medline 
Jordan PM, Fettis M, Holt JC (2015) Efferent innervation of turtle semicircular canal cristae: comparisons with bird and mouse. J Comp Neurol 523:1258-1280. CrossRef Medline

Kalluri R, Xue J, Eatock RA (2010) Ion channels set spike timing regularity of mammalian vestibular afferent neurons. J Neurophysiol 104:20342051. CrossRef Medline

Kharkovets T, Hardelin JP, Safieddine S, Schweizer M, El-Amraoui A, Petit C, Jentsch TJ (2000) KCNQ4, a K+ channel mutated in a form of dominant deafness, is expressed in the inner ear and the central auditory pathway. Proc Natl Acad Sci U S A 97:4333-4338. CrossRef Medline

Kong WJ, Egg G, Hussl B, Spoendlin H, Schrott-Fischer A (1994) Localization of chat-like immunoreactivity in the vestibular endorgans of the rat. Hear Res 75:191-200. CrossRef Medline

Kosenko A, Hoshi N (2013) A change in configuration of the calmodulinKCNQ channel complex underlies Ca2+-dependent modulation of KCNQ channel activity. PLoS One 8:e82290. CrossRef Medline

Kubo T, Ding WG, Toyoda F, Fujii Y, Omatsu-Kanbe M, Matsuura H (2015) Phosphatidylinositol4-phosphate 5-kinase prevents the decrease in the HERG potassium current induced by Gq protein-coupled receptor stimulation. J Pharmacol Sci 127:127-134. CrossRef Medline

Layton MG, Robertson D, Everett AW, Mulders WH, Yates GK (2005) Cellular localization of voltage-gated calcium channels and synaptic vesicleassociated proteins in the guinea pig cochlea. J Mol Neurosci 27:225-244. CrossRef Medline

Lerche C, Scherer CR, Seebohm G, Derst C, Wei AD, Busch AE, Steinmeyer K (2000) Molecular cloning and functional expression of KCNQ5, a potassium channel subunit that may contribute to neuronal M-current diversity. J Biol Chem 275:22395-22400. CrossRef Medline

Li GQ, Correia MJ (2011) Responses of pigeon vestibular hair cells to cholinergic agonists and antagonists. Brain Res 1373:25-38. CrossRef Medline

Li GQ, Kevetter GA, Leonard RB, Prusak DJ, Wood TG, Correia MJ (2007) Muscarinic acetylcholine receptor subtype expression in avian vestibular hair cells, nerve terminals and ganglion cells. Neuroscience 146:384-402. CrossRef Medline

Lim SB, Cleworth TW, Horslen BC, Blouin JS, Inglis JT, Carpenter MG (2016) Postural threat influences vestibular-evoked muscular responses. J Neurophysiol. Advance online publication. Retrieved January 18, 2017. doi:jn.00712.2016. CrossRef

Lipovsek M, Im GJ, Franchini LF, Pisciottano F, Katz E, Fuchs PA, Elgoyhen AB (2012) Phylogenetic differences in calcium permeability of the auditory hair cell cholinergic nicotinic receptor. Proc Natl Acad Sci U S A 109:4308-4313. CrossRef Medline

Lopez IA, Acuna D, Beltran-Parrazal L, Espinosa-Jeffrey A, Edmond J (2008) Oxidative stress and the deleterious consequences to the rat cochlea after prenatal chronic mild exposure to carbon monoxide in air. Neuroscience 151:854-867. CrossRef Medline

Luebke AE, Holt JC, Jordan PM, Wong YS, Caldwell JS, Cullen KE (2014) Loss of $\alpha$-calcitonin gene-related peptide ( $\alpha \mathrm{CGRP}$ ) reduces the efficacy of the vestibulo-ocular reflex (VOR). J Neurosci 34:10453-10458. CrossRef Medline

Lysakowski A, Goldberg JM (1997) A regional ultrastructural analysis of the cellular and synaptic architecture in the chinchilla cristae ampullares. J Comp Neurol 389:419-443. CrossRef Medline

Lysakowski A, Goldberg JM (2004) Morphophysiology of the vestibular periphery. In: The vestibular system (Highstein SM, Popper A, Fay RR, eds), pp 57-152. New York: Springer.

Lysakowski A, Gaboyard-Niay S, Calin-Jageman I, Chatlani S, Price SD, Eatock RA (2011) Molecular microdomains in a sensory terminal, the vestibular calyx ending. J Neurosci 31:10101-10114. CrossRef Medline

Marco RA, Hoffman LF, Wackym PA, Micevych PE, Popper P (1996) Distribution of calcitonin gene-related peptide immunoreactivity in vestibular efferent neurons of the chinchilla. Hear Res 97:95-101. CrossRef Medline

Marlinski V, Plotnik M, Goldberg JM (2004) Efferent actions in the chinchilla vestibular labyrinth. J Assoc Res Otolaryngol 5:126-143. CrossRef Medline

McCue MP, Guinan JJ Jr (1994) Influence of efferent stimulation on acoustically responsive vestibular afferents in the cat. J Neurosci 14:6071-6083. Medline

Meredith FL, Rennie KJ (2015) Zonal variations in K+ currents in vestibular crista calyx terminals. J Neurophysiol 113:264-276. CrossRef Medline
Meredith GE (1988) Comparative view of the central organization of afferent and efferent circuitry for the inner ear. Acta Biol Hung 39:229-249. Medline

Metts BA, Kaufman GD, Perachio AA (2006) Polysynaptic inputs to vestibular efferent neurons as revealed by viral transneuronal tracing. Exp Brain Res 172:261-274. CrossRef Medline

Meves H, Schwarz JR, Wulfsen I (1999) Separation of M-like current and ERG current in NG108-15 cells. Br J Pharmacol 127:1213-1223. CrossRef Medline

Mirakhur RK, Dundee JW (1983) Glycopyrrolate: pharmacology and clinical use. Anaesthesia 38:1195-1204. CrossRef Medline

Monk G, Peterson EH (1995) Calretinin is not specific for calyceal afferents in the semicircular canals of Pseudemys scripta. Soc Neurosci Abstr 21:918.

Morley BJ, Lysakowski A, Vijayakumar S, Menapace D, Jones TA (2016) Nicotinic acetylcholine receptors regulate vestibular afferent gain and activation timing. J Comp Neurol. Advance online publication. Retrieved January 18, 2017. doi:10.1002/cne.24131. CrossRef

Naranjo EN, Allum JH, Inglis JT, Carpenter MG (2015) Increased gain of vestibulospinal potentials evoked in neck and leg muscles when standing under height-induced postural threat. Neuroscience 293:45-54. CrossRef Medline

Ohtani M, Devau G, Lehouelleur J, Sans A (1994) Cholinergic agonists increase intracellular calcium concentration in frog vestibular hair cells. Hear Res 80:167-173. CrossRef Medline

Perachio AA, Kevetter GA (1989) Identification of vestibular efferent neurons in the gerbil: histochemical and retrograde labelling. Exp Brain Res 78:315-326. Medline

Pérez C, Limón A, Vega R, Soto E (2009) The muscarinic inhibition of the potassium M-current modulates the action-potential discharge in the vestibular primary-afferent neurons of the rat. Neuroscience 158:16621674. CrossRef Medline

Pérez C, Vega R, Soto E (2010) Phospholipase C-mediated inhibition of the $\mathrm{M}$-potassium current by muscarinic-receptor activation in the vestibular primary-afferent neurons of the rat. Neurosci Lett 468:238-242. CrossRef Medline

Pfaff D, Westberg L, Kow LM (2005) Generalized arousal of mammalian central nervous system. J Comp Neurol 493:86-91. CrossRef Medline

Popper P, Ishiyama A, Lopez I, Wackym PA (2002) Calcitonin gene-related peptide and choline acetyltransferase colocalization in the human vestibular periphery. Audiol Neurootol 7:298-302. CrossRef Medline

Popper P, Cristobal R, Wackym PA (2004) Expression and distribution of mu opioid receptors in the inner ear of the rat. Neuroscience 129:225233. CrossRef Medline

Proakis AG, Harris GB (1978) Comparative penetration of glycopyrrolate and atropine across the blood-brain and placental barriers in anesthetised dogs. Anesthesiology 48:339-344. CrossRef Medline

Pujol R, Pickett SB, Nguyen TB, Stone JS (2014) Large basolateral processes on type II hair cells are novel processing units in mammalian vestibular organs. J Comp Neurol 522:3141-3159. CrossRef Medline

Purcell IM, Perachio AA (1997) Three-dimensional analysis of vestibular efferent neurons innervating semicircular canals of the gerbil. J Neurophysiol 78:3234-3248. Medline

Rabbitt RD, Boyle R, Highstein SM (1995) Mechanical indentation of the vestibular labyrinth and its relationship to head rotation in the toadfish, Opsanus tau. J Neurophysiol 73:2237-2260. Medline

Ren XQ, Liu GX, Organ-Darling LE, Zheng R, Roder K, Jindal HK, Centracchio J, McDonald TV, Koren G (2010) Pore mutants of HERG and KvLQT1 downregulate the reciprocal currents in stable cell lines. Am J Physiol Heart Circ Physiol 299:H1525-H1534. CrossRef Medline

Rennie KJ, Weng T, Correia MJ (2001) Effects of KCNQ channel blockers on $\mathrm{K}(+)$ currents in vestibular hair cells. Am J Physiol Cell Physiol 280: C473-C480. Medline

Roberts BL, Russell IJ (1972) The activity of lateral-line efferent neurones in stationary and swimming dogfish. J Exp Biol 57:435-448. Medline

Rossi ML, Prigioni I, Valli P, Casella C (1980) Activation of the efferent system in the isolated frog labyrinth: effects on the afferent EPSPs and spike discharge recorded from single fibres of the posterior nerve. Brain Res 185:125-137. CrossRef Medline

Ryan AF, Simmons DM, Watts AG, Swanson LW (1991) Enkephalin mRNA production by cochlear and vestibular efferent neurons in the gerbil brainstem. Exp Brain Res 87:259-267. Medline

Sadeghi SG, Chacron MJ, Taylor MC, Cullen KE (2007a) Neural variability, 
detection thresholds, and information transmission in the vestibular system. J Neurosci 27:771-781. CrossRef Medline

Sadeghi SG, Minor LB, Cullen KE (2007b) Response of vestibular-nerve afferents to active and passive rotations under normal conditions and after unilateral labyrinthectomy. J Neurophysiol 97:1503-1514. CrossRef Medline

Sans A, Highstein SM (1984) New ultrastructural features in the vestibular labyrinth of the toadfish, Opsanus tau. Brain Res 308:191-195. CrossRef Medline

Schroeder BC, Hechenberger M, Weinreich F, Kubisch C, Jentsch TJ (2000) KCNQ5, a novel potassium channel broadly expressed in brain, mediates M-type currents. J Biol Chem 275:24089-24095. CrossRef Medline

Schwarz AJ, Straumann D, Tarnutzer AA (2015) Diurnal fluctuations of verticality perception-lesser precision immediately after waking up in the morning. Front Neurol 6:195. CrossRef Medline

Selyanko AA, Delmas P, Hadley JK, Tatulian L, Wood IC, Mistry M, London B, Brown DA (2002) Dominant-negative subunits reveal potassium channel families that contribute to M-like potassium currents. J Neurosci 22:RC212. Medline

Sewell WF, Starr PA (1991) Effects of calcitonin gene-related peptide and efferent nerve stimulation on afferent transmission in the lateral line organ. J Neurophysiol 65:1158-1169. Medline

Sihn CR, Kim HJ, Woltz RL, Yarov-Yarovoy V, Yang PC, Xu J, Clancy CE, Zhang XD, Chiamvimonvat N, Yamoah EN (2016) Mechanisms of calmodulin regulation of different isoforms of Kv7.4 K+ channels. J Biol Chem 291:2499-2509. CrossRef Medline

Smith CA, Rasmussen GL (1968) Nerve endings in the maculae and cristae of the chinchilla vestibule, with a special reference to the efferents. In: The third symposium on the role of the vestibular organs in space exploration: NASA SP-152. Washington DC: U.S. Government Printing Office, pp 183-201.

Søgaard R, Ljungstrøm T, Pedersen KA, Olesen SP, Jensen BS (2001) KCNQ4 channels expressed in mammalian cells: functional characteristics and pharmacology. Am J Physiol Cell Physiol 280:C859-C866. Medline

Sousa AD, Andrade LR, Salles FT, Pillai AM, Buttermore ED, Bhat MA,
Kachar B (2009) The septate junction protein caspr is required for structural support and retention of KCNQ4 at calyceal synapses of vestibular hair cells. J Neurosci 29:3103-3108. CrossRef Medline

Spitzmaul G, Tolosa L, Winkelman BH, Heidenreich M, Frens MA, Chabbert C, de Zeeuw CI, Jentsch TJ (2013) Vestibular role of KCNQ4 and KCNQ5 K+ channels revealed by mouse models. J Biol Chem 288:93349344. CrossRef Medline

Sridhar TS, Brown MC, Sewell WF (1997) Unique postsynaptic signaling at the hair cell efferent synapse permits calcium to evoke changes on two time scales. J Neurosci 17:428-437. Medline

Storper IS, Spitzer JB, Scanlan M (1998) Use of glycopyrrolate in the treatment of Meniere's disease. Laryngoscope 108:1442-1445. CrossRef Medline

Sugai T, Sugitani M, Ooyama H (1991) Effects of activation of the divergent efferent fibers on the spontaneous activity of vestibular afferent fibers in the toad. Jpn J Physiol 41:217-232. CrossRef Medline

Terry RJ (1920) The relation of the facial nerve and otic capsule. Anat Rec 17:235-242. CrossRef

Vega R, Soto E (2003) Opioid receptors mediate a postsynaptic facilitation and a presynaptic inhibition at the afferent synapse of axolotl vestibular hair cells. Neuroscience 118:75-85. CrossRef Medline

Verbitsky M, Rothlin CV, Katz E, Elgoyhen AB (2000) Mixed nicotinicmuscarinic properties of the alpha9 nicotinic cholinergic receptor. Neuropharmacol 39:2515-2524. CrossRef

Vernino S, Amador M, Luetje CW, Patrick J, Dani JA (1992) Calcium modulation and high calcium permeability of neuronal nicotinic acetylcholine receptors. Neuron 8:127-134. CrossRef Medline

Vernino S, Rogers M, Radcliffe KA, Dani JA (1994) Quantitative measurement of calcium flux through muscle and neuronal nicotinic acetylcholine receptors. J Neurosci 14:5514-5524. Medline

Wackym PA, Chen CT, Ishiyama A, Pettis RM, López IA, Hoffman L (1996) Muscarinic acetylcholine receptor subtype mRNAs in the human and rat vestibular periphery. Cell Biol Int 20:187-192. CrossRef Medline

Yates BJ, Miller AD, Lucot JB (1998) Physiological basis and pharmacology of motion sickness: an update. Brain Res Bull 47:395-406. CrossRef Medline 